\title{
Article \\ Usher Syndrome Belongs to the Genetic Diseases Associated with Radiosensitivity: Influence of the ATM Protein Kinase
}

\author{
Joëlle Al-Choboq ${ }^{1}{ }^{\mathbb{C}}$, Mélanie L. Ferlazzo ${ }^{1}$, Laurène Sonzogni ${ }^{1}$, Adeline Granzotto ${ }^{1}$, Laura El-Nachef ${ }^{1}$, \\ Mira Maalouf ${ }^{2}$, Elise Berthel ${ }^{1}(\mathbb{B})$ and Nicolas Foray ${ }^{1, *}$ (D)
}

1 Inserm, U1296 Unit, Radiation: Defense, Health and Environment, Centre Léon-Bérard, 28 rue Laennec, 69008 Lyon, France; joelle.al-choboq@inserm.fr (J.A.-C.); melanie.ferlazzo@inserm.fr (M.L.F.); laurene.sonzogni@inserm.fr (L.S.); adeline.granzotto@inserm.fr (A.G.); laura.el-nachef@inserm.fr (L.E.-N.); elise.berthel@inserm.fr (E.B.)

2 Department of Chemistry and Biochemistry, Faculty of Sciences II, Lebanese University, Fanar 1202, Lebanon; mira.n.maalouf@gmail.com

* Correspondence: Nicolas.foray@inserm.fr; Tel.: +33-4-78-78-28-28

Citation: Al-Choboq, J.; Ferlazzo, M.L.; Sonzogni, L.; Granzotto, A.;

El-Nachef, L.; Maalouf, M.; Berthel,

E.; Foray, N. Usher Syndrome

Belongs to the Genetic Diseases

Associated with Radiosensitivity:

Influence of the ATM Protein Kinase.

Int. J. Mol. Sci. 2022, 23, 1570

https://doi.org/10.3390/

ijms23031570

Academic Editor:

Dimitris Emfietzoglou

Received: 1 January 2022

Accepted: 27 January 2022

Published: 29 January 2022

Publisher's Note: MDPI stays neutral with regard to jurisdictional claims in published maps and institutional affiliations.

Copyright: (c) 2022 by the authors Licensee MDPI, Basel, Switzerland. This article is an open access article distributed under the terms and conditions of the Creative Commons Attribution (CC BY) license (https:// creativecommons.org/licenses/by/ $4.0 /)$.

\begin{abstract}
Usher syndrome (USH) is a rare autosomal recessive disease characterized by the combination of hearing loss, visual impairment due to retinitis pigmentosa, and in some cases vestibular dysfunctions. Studies published in the 1980s reported that USH is associated with cellular radiosensitivity. However, the molecular basis of this particular phenotype has not yet been documented. The aim of this study was therefore to document the radiosensitivity of USH1-a subset of USH-by examining the radiation-induced nucleo-shuttling of ATM (RIANS), as well as the functionality of the repair and signaling pathways of the DNA double-strand breaks (DSBs) in three skin fibroblasts derived from USH1 patients. The clonogenic cell survival, the micronuclei, the nuclear foci formed by the phosphorylated forms of the $\mathrm{X}$ variant of the $\mathrm{H} 2 \mathrm{~A}$ histone ( $\mathrm{YH} 2 \mathrm{AX}$ ), the phosphorylated forms of the ATM protein (pATM), and the meiotic recombination 11 nuclease (MRE11) were used as cellular and molecular endpoints. The interaction between the ATM and USH1 proteins was also examined by proximity ligation assay. The results showed that USH1 fibroblasts were associated with moderate but significant radiosensitivity, high yield of micronuclei, and impaired DSB recognition but normal DSB repair, likely caused by a delayed RIANS, suggesting a possible sequestration of ATM by some USH1 proteins overexpressed in the cytoplasm. To our knowledge, this report is the first radiobiological characterization of cells from USH1 patients at both molecular and cellular scales.
\end{abstract}

Keywords: Usher syndrome; radiosensitivity; DNA double-strand breaks; ATM; ionizing radiation

\section{Introduction}

Usher syndrome (USH) is the most frequent cause of combined deafness and blindness in humans. USH is a very rare genetic disorder that combines congenital sensorineural hearing loss of variable severity, retinitis pigmentosa (RP) and, in some cases, vestibular dysfunctions [1,2]. While pigmentary changes in the retinas of some deaf children were first reported by the German researchers Albert Von Gräfe [3] and Richard Liebreich [4,5] before 1860, history retained the name of the Scottish ophthalmologist Charles Howard Usher, who published a princeps paper about the transmission of the disease from 69 cases in 1914 [6].

USH is considered to be an autosomal recessive disease with a prevalence between 3 and 17 in 100,000 individuals [7,8]. Three USH subtypes have been described-USH1, USH2, and USH3 - based on the degree of hearing loss, the age of onset of RP, and the presence of vestibular dysfunction [9]. USH1, which accounts for $\sim 35 \%$ of USH cases, is the most severe USH subtype, with severe-to-profound congenital hearing loss and prepubertal onset of RP [10]. The different forms of USH1 are caused by mutations of at least six genes [10-12], 
encoding the actin-based motor myosin VIIA protein (USH1B/MYO7A) [13], the harmonin protein (USH1C/Harmonin) [14], two cadherin-related proteins-cadherin-23 (USH1D/CDH23) [15] and protocadherin-15 (USH1F/PCDH15) [16]—and the scaffold protein containing ankyrin repeats and sterile alpha motif (SAM) domain (USH1G/SANS) [17]. The locus previously called USH1A does not exist [18].

In the 1980s, skin fibroblasts derived from USH patients were reported to be radiosensitive in vitro $[19,20]$ (Table 1). Although these findings suggest the occurrence of some complications during or after anticancer radiotherapy, USH patients have not necessarily been subjected to radiotherapy, since USH has not been specifically associated with high cancer proneness. Nevertheless, it is noteworthy that RP can be associated with several fundus tumors, including giant drusen-resembling astrocytoma [21] or rectal adenocarcinoma [22]. Furthermore, some adverse tissue reactions following radiotherapy against laryngeal cancer have been reported in one USH patient [23]. Hence, the response of USH patients to ionizing radiation (IR) may represent both a scientific and medical issue. Further investigations about the radiosensitivity of USH cells are important inasmuch as this syndrome has been classified among the 10 genetic syndromes associated with the highest radiosensitivity in humans [24]. Unfortunately, no mechanistic model has yet been proposed to explain the potential abnormal response to IR associated with USH.

Table 1. Major studies dealing with the radiobiological characterization of USH cells.

\begin{tabular}{|c|c|c|c|}
\hline USH Cells & Techniques & Conclusions & Reference \\
\hline $\begin{array}{l}\text { Lymphoblastoid cells: GM03853, } \\
\text { GM03892, RB4361, RB5062, } \\
\text { RB5204, RB5207, RB5333, RB5360; } \\
\text { Skin fibroblasts: GM03854, } \\
\text { GM03889, GM03891. }\end{array}$ & $\begin{array}{l}\text { Exclusion } \\
\text { assay }\end{array}$ & $\begin{array}{l}\text { Low } \\
\text { radiosensitivity }\end{array}$ & [21] \\
\hline $\begin{array}{l}\text { Skin fibroblasts: GM03889, } \\
\text { GM03854, GM03891. }\end{array}$ & Colony formation & $\begin{array}{c}\text { Severe } \\
\text { radiosensitivity }\end{array}$ & [20] \\
\hline $\begin{array}{l}\text { Skin fibroblasts: GM03889, } \\
\text { GM03854, GM03891. }\end{array}$ & $\begin{array}{l}\text { Colony formation } \\
\gamma \mathrm{H} 2 \mathrm{AX}, \mathrm{pATM}, \\
\text { and MRE11 foci }\end{array}$ & $\begin{array}{l}\text { Moderate } \\
\text { radiosensitivity }\end{array}$ & This study \\
\hline
\end{tabular}

There is increasing evidence that the repair and signaling of the DNA double-strand breaks (DSBs) - the radiation-induced DNA damage the most strongly linked to the radiation-induced (RI) cell death [25]; however, the aforementioned USH proteins are not known to be involved in these processes. Moreover, the USH proteins are mostly localized in the cytoplasm, which contradicts the current paradigm that the radiosensitivity phenotype should be associated with the defect of DSB repair and signaling, whose proteins are generally localized in the nucleus [25]. Some other genetic syndromes have been already reported to be associated with both cellular radiosensitivity and mutations of cytoplasmic proteins; this is notably the case of Huntington's disease (HD) [26], tuberous sclerosis (TSC) [27], neurofibromatosis type 1 (NF1) [28], and a subset of xeroderma pigmentosum D (XPD) [29]. In these diseases, abnormal response to IR was found to be generated by an overexpression of the cytoplasmic forms of the mutated protein causing the disease and its capacity to bind ATM - a major kinase activated in the early steps of the non-homologous end-joining (NHEJ), which is the predominant DSB signaling and repair pathway in humans.

The link between an abnormal response to IR and the overexpression of some ATM substrates localized in the cytoplasm has been integrated in a mechanistic model based on the radiation-induced ATM nucleo-shuttling (RIANS). Relevant for both high- and lowdose radiobiological phenomena, the RIANS model has been proposed to describe, predict, and quantify the risk linked to any exposure to IR [15-17]. In the framework of the RIANS model, the oxidative stress caused by IR induces the monomerization of the ATM dimers in the cytoplasm. The resulting ATM monomers diffuse in the nucleus and phosphorylate the 
$\mathrm{H} 2 \mathrm{AX}$ histone variant ( $\gamma \mathrm{H} 2 \mathrm{AX})$ at DSB sites, triggering the formation of nuclear $\gamma \mathrm{H} 2 \mathrm{AX}$ foci, as easily quantifiable by immunofluorescence. The formation of nuclear $\gamma \mathrm{H} 2 \mathrm{AX}$ foci is considered to be an early recognition step of the RI DSBs repaired by NHEJ [7,15-20]. During the DSB repair process, two ATM monomers reassociate on the DSB sites and form the nuclear trans-autophosphorylated ATM (pATM) foci, which are also visible via immunofluorescence. Any delay in the RIANS leads to a radiosensitivity phenotype. By considering the nuclear $\gamma \mathrm{H} 2 \mathrm{AX}$ and pATM foci as endpoints, the early $(10 \mathrm{~min}, 1 \mathrm{~h})$ postirradiation time data provide information about the DSB recognition process, while the late (24 h) post-irradiation time data characterize the DSB repair step [16,21]. The RIANS model provides a statistically robust prediction of post-radiotherapy radiosensitivity [30-34] and a unified model to explain radiosensitivity in a number of genetic syndromes, including HD, TSC, NF1, and XPD [26-29]. In the framework of the RIANS model and its related biomarkers, this study aims to provide-for the first time to our knowledge-a radiobiological characterization of USH1 fibroblasts.

\section{Results}

\subsection{Cellular Radiosensitivity of USH1 Fibroblasts}

In order to evaluate the cellular radiosensitivity of USH1, the clonogenic survival assay was applied to three USH1 fibroblast cell lines (GM03854, GM03889, and GM03891), but also to four radioresistant (1BR3, 149BR, MRC5, and Hs27), two hyper-radiosensitive ATM-mutated (AT4BI and AT5BI), one HD (GM21757), one TSC (GM06100), and two XPD (XP16BR and XP17PV) fibroblast cell lines (Figure 1).
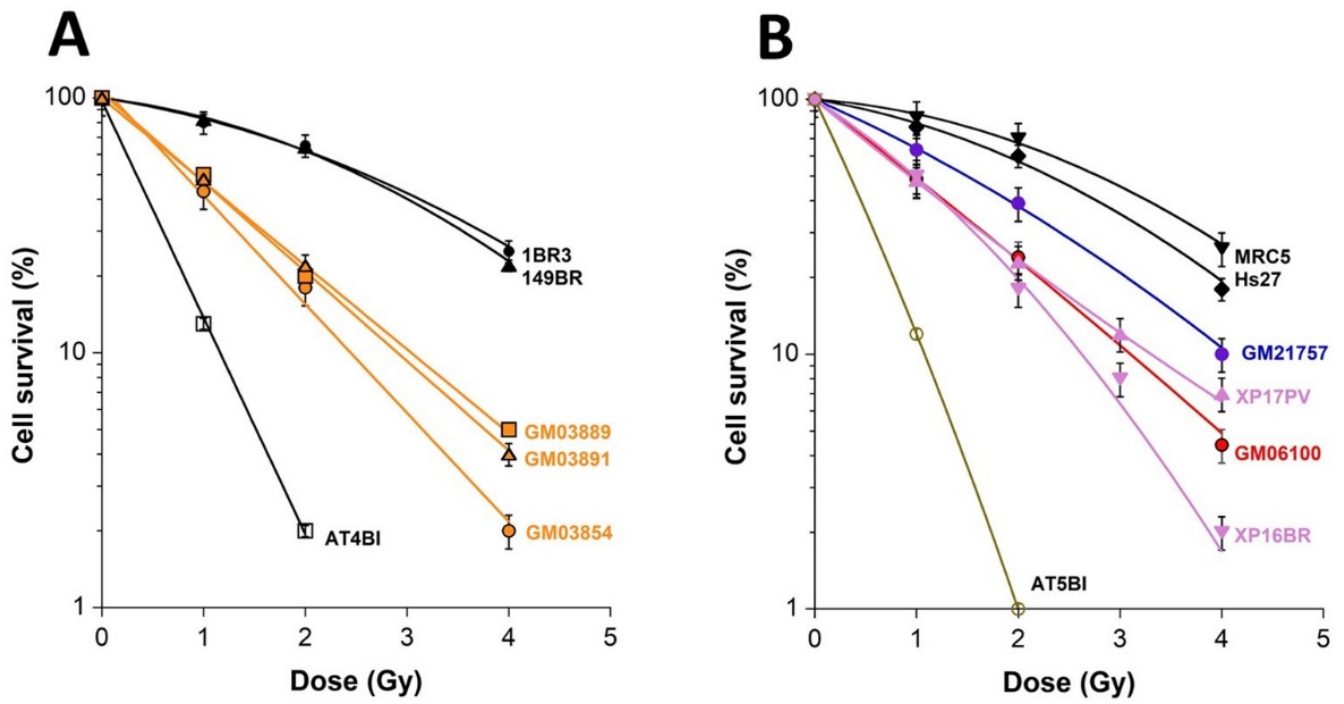

Figure 1. Clonogenic cell survival in USH1 fibroblasts: A clonogenic cell survival assay was applied to the radioresistant controls 1BR3 and 149BR, the hyper-radiosensitive ATM-mutated AT4BI, and the three USH1 (GM03854, GM03889, and GM03891) fibroblast cell lines (A), and to the radioresistant controls MRC5 and Hs27, the hyper-radiosensitive ATM-mutated AT5BI, the HD (GM21757), the TSC (GM06100), and two XPD (XP16BR and XP17PV) fibroblast cell lines (B). Each plot represents the mean \pm SEM of three replicates. Survival data were fitted to the LQ model.

The cellular radiosensitivity assessed in USH1 fibroblasts appeared to be intermediatehigher than that of radioresistant cells but lower than that of the hyper-radiosensitive fibroblasts. By using the cell survival fraction at 2 Gy (SF2) values as a quantitative parameter of radiosensitivity, the SF2 values of the GM03854, GM03889, and GM03891 cells were found to be $18 \pm 3 \%, 20 \pm 1 \%$, and $22 \pm 3 \%$, respectively, while the average SF2 values of the radioresistant and hypersensitive controls were $65 \pm 3 \%$ and $2.2 \pm 1.0 \%$, respectively. These findings support a moderate but significant radiosensitivity of the USH1 cells tested-significantly higher $(p<0.01)$ than that of radioresistant, controls 
but significantly lower $(p<0.02)$ than that of hyper-radiosensitive cells (Figure $1 \mathrm{~A}, \mathrm{~B})$. The LQ parameters of GM03854, GM03889, and GM03891 cells were $\alpha=0.81 \pm 0.02$ $\mathrm{Gy}^{-1}$ and $\beta=0.029 \pm 0.01 \mathrm{~Gy}^{-2}, \alpha=0.66 \pm 0.07 \mathrm{~Gy}^{-1}$ and $\beta=0.052 \pm 0.04 \mathrm{~Gy}^{-2}$. and $\alpha=0.71 \pm 0.01 \mathrm{~Gy}^{-1}$ and $\beta=0.023 \pm 0.01 \mathrm{~Gy}^{-2}(\mathrm{r}=0.99$ for the three data fits), respectively. Interestingly, the cellular radiosensitivity of USH1 fibroblasts was found to be in the same range of that of HD, TSC, and XPD cells, in agreement with published reports $[26,27,29]$ (Figure 1B).

\subsection{Abnormally High Levels of Micronuclei in USH1 Fibroblasts}

Micronuclei lead to irreversibly damaged chromosomal fragments, causing mitotic death. Micronuclei generally result from the propagation of unrepaired DSBs all along the cell cycle, and may lead to lagging chromosomes or metaphase bridges. Although these latter two specific cytogenetic events have been observed in USH1 cells, the fact that the great majority of cells were irradiated in G0/G1 precluded a robust analysis of the origin of each micronucleus observed. Conversely, whatever their origin, micronuclei have been shown to be quantitatively correlated with cellular radiosensitivity [25], and can be quantified thanks to the $4^{\prime}, 6^{\prime}$ diamidino-2-phenyl-indole (DAPI) counterstaining under the same conditions as all of the immunofluorescence data (see Section 4). The number of micronuclei was assessed before or after $2 \mathrm{~Gy}$ followed by $24 \mathrm{~h}$ in USH1 cells. With regard to spontaneous micronuclei, no significant difference was found between USH1 cells and radioresistant controls $(p>0.05)$, while the number of spontaneous micronuclei per 100 cells was found to be significantly higher in the two hyper-radiosensitive ATM-mutated cells $(p<0.001)$ (data not shown). With regard to micronuclei assessed $24 \mathrm{~h}$ post-irradiation, the number of micronuclei per 100 cells was found to be significantly higher $(p<0.01)$ than that of radioresistant controls, but lower $(p<0.001)$ than that observed in the hyperradiosensitive ATM-mutated cells $(p<0.04)$ (Figure $2 \mathrm{~A})$, supporting a significant genomic instability in the USH1 cells tested. Again, the data obtained from the HD, TSC, and XPD cells were in the same range as those from the USH1 cells (Figure 2B).
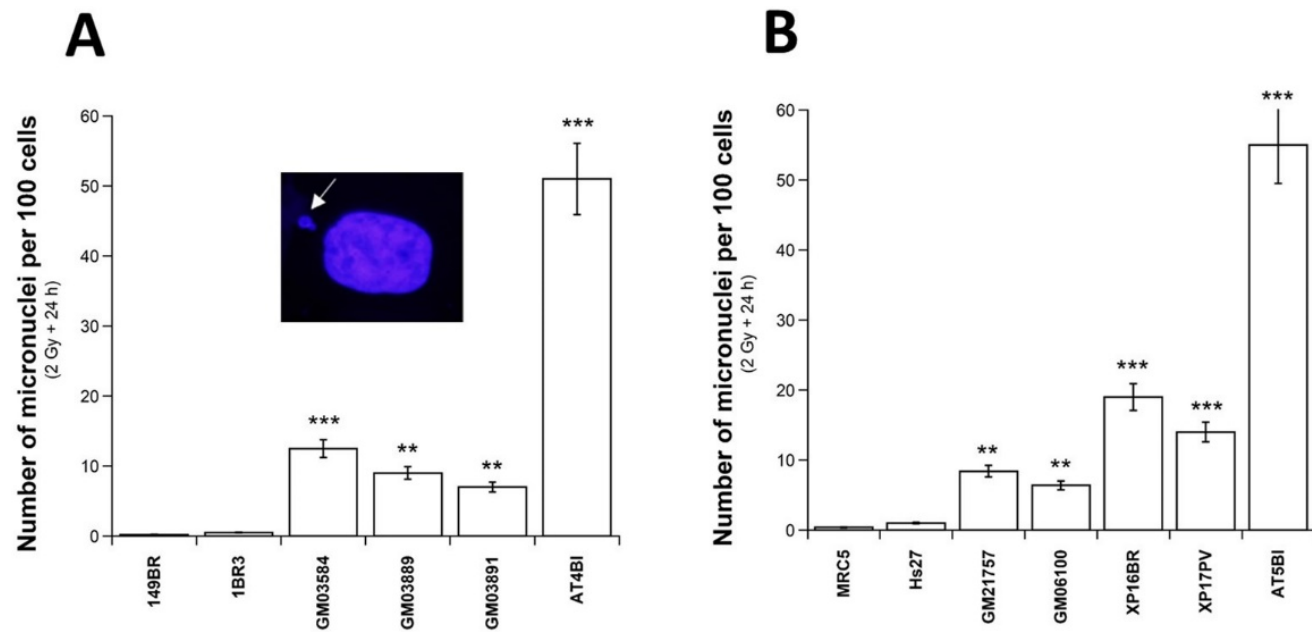

Figure 2. Micronuclei in USH1 fibroblasts: Number of micronuclei per 100 cells assessed $24 \mathrm{~h}$ after 2 Gy X-rays in the radioresistant controls 1BR3 and 149BR, the hyper-radiosensitive ATM-mutated AT4BI, and the three USH1 (GM03854, GM03889, and GM03891) fibroblast cell lines (A), and in the radioresistant controls MRC5 and Hs27, the hyper-radiosensitive ATM-mutated AT5BI, the HD (GM21757), the TSC (GM06100), and two XPD (XP16BR and XP17PV) fibroblast cell lines (B). Each plot represents the mean \pm SEM of three replicates. The insert shows a representative example of a micronucleus observed via DAPI counterstaining. Asterisks represent the statistically significant differences from radioresistant controls, expressed as $p$-values ( 2 and 3 asterisks correspond to $p<0.01$ and $p<0.001$, respectively). 
Our previous studies found a quantified correlation between SF2 and micronuclei assessed after $2 \mathrm{~Gy}$, followed by $24 \mathrm{~h}$ of repair, in a collection of human fibroblasts showing a wide range of radiosensitivity and representing 20 genetic diseases [26-29,35]. The USH1 data were found to be in full agreement with the formula linking micronuclei to SF2 values, supporting the quantitative relevance of our findings (Figure S1).

\subsection{Abnormal Number of $\gamma H 2 A X$ Foci after Irradiation in USH1 Fibroblasts}

Since micronuclei result from unrepaired DSBs, the recognition and repair of radiationinduced DSBs were investigated in USH1 fibroblasts. The kinetics of appearance/disappearance of nuclear $\gamma \mathrm{H} 2 \mathrm{AX}$ foci provide information about DSB recognition (early foci) and repair (late foci) [34]. Under our conditions, even if some spontaneous $\gamma \mathrm{H} 2 \mathrm{AX}$ foci were observed in the three USH1 fibroblasts (GM03889: $0.3 \pm 0.1$, GM03854: $0.4 \pm 0.07$, and GM03891: $0.3 \pm 0.09 \gamma \mathrm{H} 2 \mathrm{AX}$ foci per cell), their number was not significantly different from in the radioresistant controls ( $0.2 \pm 0.3$ on average; $p>0.1$; Figure 3$)$. In the radioresistant controls, the number of $\gamma \mathrm{H} 2 \mathrm{AX}$ foci measured $10 \mathrm{~min}$ after $2 \mathrm{~Gy}$ was $79 \pm 4$ per cell, in very good agreement with the value of $37 \pm 4$ per Gy per cell published previously [35]. The number of induced $\gamma \mathrm{H} 2 \mathrm{AX}$ foci measured 10 min post-irradiation in the three USH1 fibroblasts was systematically lower than in the radioresistant controls (GM03889: $33.6 \pm 6.9$, GM03854: $41 \pm 5.7$, and GM03891: $36.3 \pm 3.8 \gamma \mathrm{H} 2 \mathrm{AX}$ foci per cell; $p<0.01$ ) (Figure 3A,B).
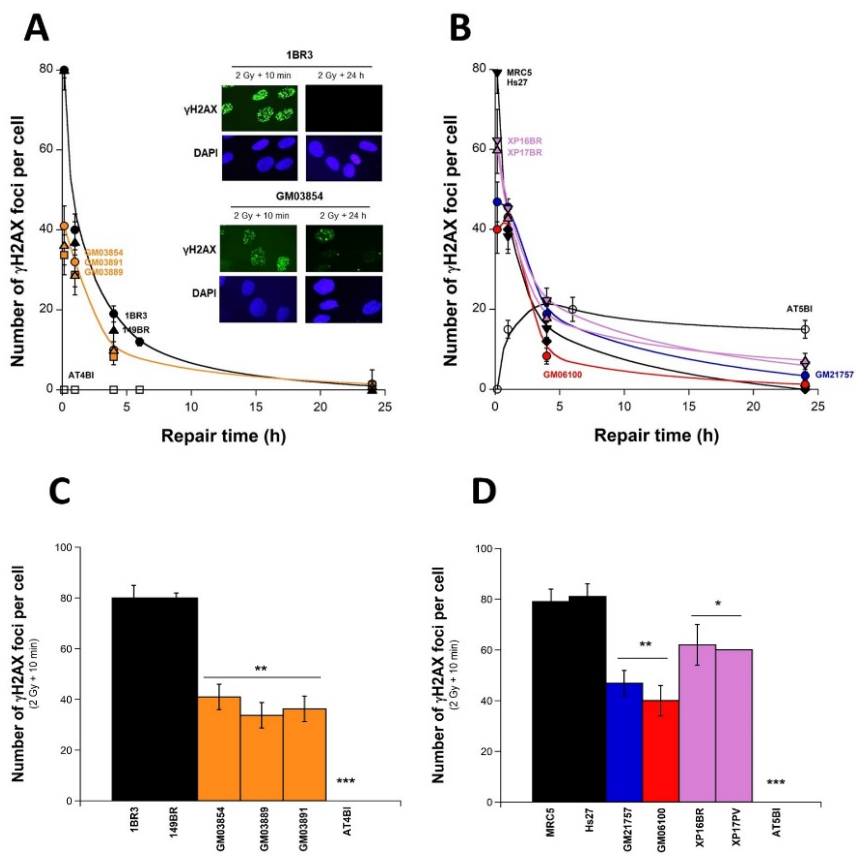

Figure 3. Kinetics of the appearance/disappearance of $\gamma \mathrm{H} 2 \mathrm{AX}$ foci in USH1 fibroblasts: The number of $\gamma \mathrm{H} 2 \mathrm{AX}$ foci was plotted against post-irradiation time. Data were obtained from the radioresistant controls 1BR3 and 149BR, the hyper-radiosensitive ATM-mutated AT4BI, and the three USH1 (GM03854, GM03889, and GM03891) fibroblast cell lines (A), and from the radioresistant controls MRC5 and Hs27, the hyper-radiosensitive ATM-mutated AT5BI, the HD (GM21757), the TSC (GM06100), and two XPD (XP16BR and XP17PV) fibroblast cell lines (B). Panels (C,D) represent the 10 min post-irradiation data only. Each plot represents the mean $\pm \mathrm{SEM}$ of three replicates. Data were fitted to Bodgi's formula [36]. The insert shows a representative illustration of DAPI-stained nuclei and $\gamma \mathrm{H} 2 \mathrm{AX}$ foci observed at $10 \mathrm{~min}$ and $24 \mathrm{~h}$ post-irradiation (2 Gy X-rays) in the indicated cell lines. Asterisks represent statistically significant differences from radioresistant controls, expressed as $p$-values $(1,2$, and 3 asterisks correspond to $p<0.05, p<0.01$, and $p<0.001$, respectively).

In order to better illustrate these differences, the histograms shown in Figure 3C,D reproduce the $10 \mathrm{~min}$ data only. No difference was found between the size of nuclei in USH1 and control cells. Our findings therefore suggest an impairment in the DSB 
recognition. At $24 \mathrm{~h}$ post-irradiation, the USH1 fibroblasts showed systematically more $\gamma \mathrm{H} 2 \mathrm{AX}$ foci $24 \mathrm{~h}$ post-irradiation (GM03889: $1.2 \pm$ 0.2, GM03854: $1.5 \pm 0.4$, and GM03891: $0.9 \pm 0.1 \gamma \mathrm{H} 2 \mathrm{AX}$ foci per cell) than the radioresistant controls $(0 \pm 0.5 \gamma \mathrm{H} 2 \mathrm{AX}$ foci per cell); however, these differences were at the limit of significance $(p=0.05)$ (Figure 3A,B). Altogether, these data suggest a lack of complete DSB recognition without any significant DSB repair defect. Since cellular radiosensitivity associated with no significant DSB repair defect has already been reported in other genetic syndromes-notably in the HD, TSC, NF1, and XPD fibroblasts [26-29]—-we examined the $\gamma \mathrm{H} 2 \mathrm{AX}$ foci kinetics in cells derived from these syndromes. The HD, TSC, and XPD cells showed $\gamma \mathrm{H} 2 \mathrm{AX}$ foci kinetics similar to those obtained with the USH1 cells tested, as with survival and micronuclei data (Figure 3B).

In order to once again consolidate the whole quantitative coherence of our USH1 data, the $\gamma \mathrm{H} 2 \mathrm{AX}$ foci and the corresponding SF2 data shown in Figure 1 were plotted on the same graph (Figure S2). The SF2 and $\gamma \mathrm{H} 2 \mathrm{AX}$ data obtained from the three USH1 fibroblasts (GM03854, GM03889, and GM03891) were found to be in good agreement with the quantitative correlation obtained from a collection of human fibroblasts showing a wide range of radiosensitivity and representing 20 genetic syndromes [26-29,35] (Figure S2).

\subsection{Abnormal Number of $p$ ATM Foci after Irradiation in USH1 Fibroblasts}

As described above, the number of induced $\gamma \mathrm{H} 2 \mathrm{AX}$ foci measured $10 \mathrm{~min}$ after irradiation in USH1 fibroblasts was found to be systematically lower than in the radioresistant controls. As previously described, these data do not suggest that fewer DSBs were physically induced in USH1 cells but, rather, that fewer DSBs were recognized by the NHEJ pathway [34]. Based on our historical data, an exposure to $2 \mathrm{~Gy}$ X-rays generally results in the formation of $\sim 40 \mathrm{pATM}$ foci per cell at $10 \mathrm{~min}$ post-irradiation in radioresistant controls. This number progressively decreased with repair time, and was not found to be different from zero at $24 \mathrm{~h}$ post-irradiation [29]. In this study, data obtained with the radioresistant control cell line reached similar conclusions ( $44 \pm 8$ and $1 \pm 2$ pATM foci per cell at $10 \mathrm{~min}$ and $24 \mathrm{~h}$ post-irradiation, respectively) (Figure 4A,B). In order to better illustrate these differences, the histograms shown in Figure 4C,D reproduce the 10 min data only.

In USH1 fibroblasts, the number of pATM foci per cell observed 10 min post-irradiation was found to be significantly lower than in control fibroblasts (GM03889: $11.7 \pm 7.4$, GM03891: $20 \pm 0$, and GM03854: $6.3 \pm 3.4$ and 1BR3: $44 \pm 8 ; p<0.001$ ). A similar conclusion was reached with pATM foci data assessed at $1 \mathrm{~h}$ post-irradiation, in agreement with $\gamma \mathrm{H} 2 \mathrm{AX}$ data, and supporting the notion that the USH1 fibroblasts elicited abnormal ATM nuclear kinase activity in response to radiation (Figure 4A). The HD, TSC, and XPD cells also showed lower numbers of early PATM foci than in radioresistant controls (Figure 4B).

In order to once again consolidate the whole quantitative coherence of our USH1 data, the pATM foci obtained 10 min post-irradiation and the corresponding SF2 data shown in Figure 1 were plotted on the same graph (Figure S3). The SF2 and the early pATM data obtained from the three USH1 fibroblasts (GM03854, GM03889, and GM03891) were found to be in agreement with the quantitative correlation obtained from a collection of human fibroblasts showing a wide range of radiosensitivity, and representing $\sim 20$ genetic diseases [26-29,35] (Figure S3). 

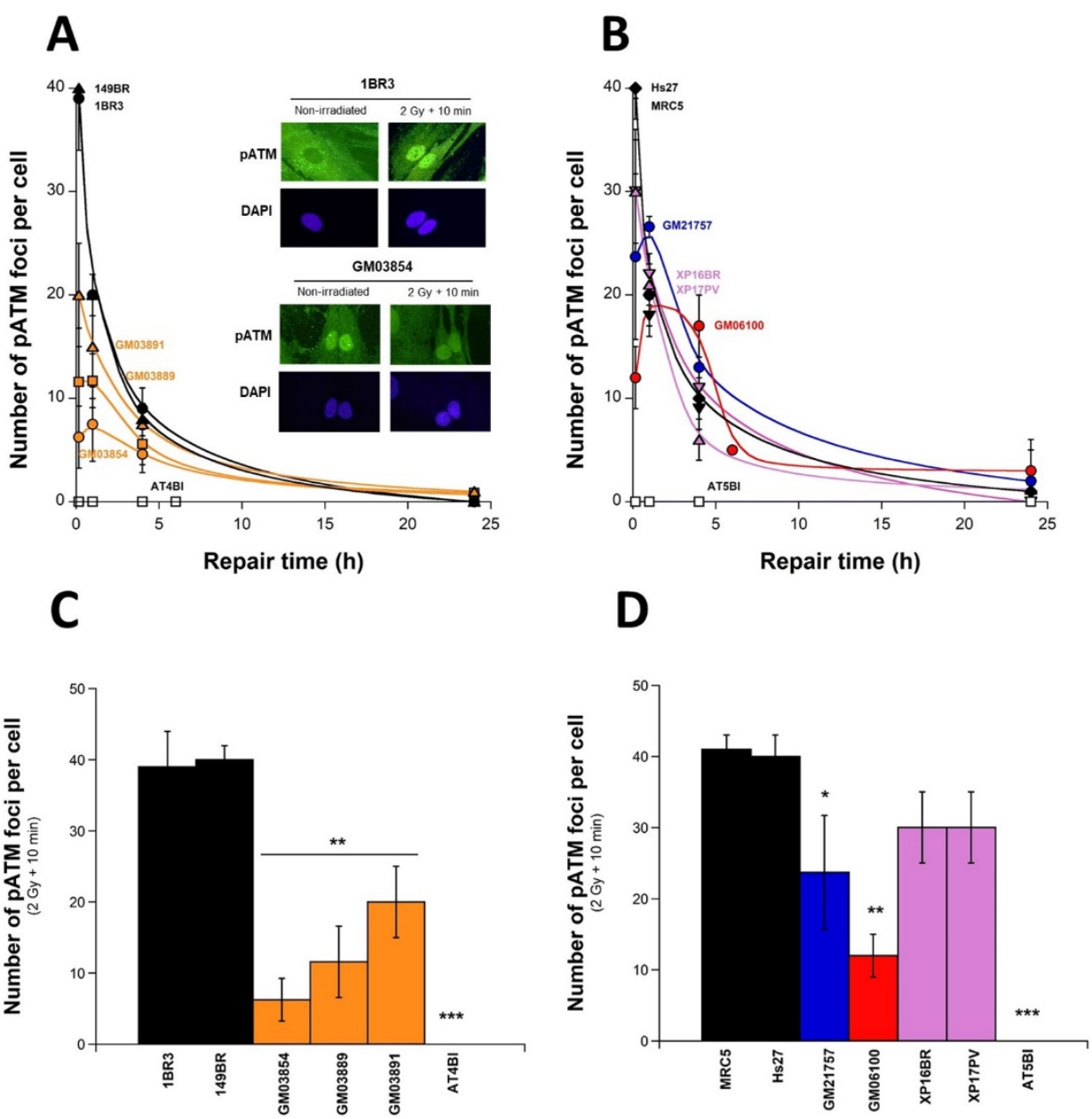

Figure 4. Kinetics of the appearance/disappearance of pATM foci in USH1 fibroblasts: The number of pATM foci was plotted against post-irradiation time. Data were obtained from the radioresistant controls 1BR3 and 149BR, the hyper-radiosensitive ATM-mutated AT4BI, and the three USH1 (GM03854, GM03889, and GM03891) fibroblast cell lines (A), and from the radioresistant controls MRC5 and Hs27, the hyper-radiosensitive ATM-mutated AT5BI, the HD (GM21757), the TSC (GM06100), and two XPD (XP16BR and XP17PV) fibroblast cell lines (B). Panels (C,D) represent the 10 min postirradiation data only. Each plot represents the mean \pm SEM of three replicates. Data were fitted to Bodgi's formula [36]. The insert shows a representative illustration of DAPI-stained nuclei and pATM foci observed at $10 \mathrm{~min}$ post-irradiation (2 Gy X-rays) in the indicated cell lines. Asterisks represent the statistically significant differences from radioresistant controls, expressed as $p$-values $(1,2$, and 3 asterisks correspond to $p<0.05, p<0.01$, and $p<0.001$, respectively).

In USH1 fibroblasts, the number of pATM foci per cell observed 10 min post-irradiation was found to be significantly lower than in control fibroblasts (GM03889: $11.7 \pm 7.4$, GM03891: $20 \pm$ 0; GM03854: $6.3 \pm 3.4$, and 1BR3: $44 \pm 8 ; p<0.001$ ). A similar conclusion was reached with PATM foci data assessed at $1 \mathrm{~h}$ post-irradiation, in agreement with $\gamma \mathrm{H} 2 \mathrm{AX}$ data, and supporting the notion that the USH1 fibroblasts elicited abnormal ATM nuclear kinase activity in response to radiation (Figure 4A). The HD, TSC, and XPD cells also showed lower numbers of early pATM foci than in radioresistant controls (Figure 4B). In order to consolidate the whole quantitative coherence of our USH1 data, the pATM foci obtained 10 min post-irradiation and the corresponding SF2 data shown in Figure 1 were plotted on the same graph (Figure S3). The SF2 and the early pATM data obtained from the three USH1 fibroblasts (GM03854, GM03889, and GM03891) were found to be in agreement with the quantitative correlation obtained from a collection of human fibroblasts showing a wide range of radiosensitivity and representing 20 genetic diseases [26-29,35] (Figure S3). 


\subsection{Abnormal Number of MRE11 Foci after Irradiation in USH1 Fibroblasts}

The MRE11 protein is a component of the RAD50-MRE11-NBS1 complex that forms nuclear foci after genotoxic stress. The formation of MRE11 foci after irradiation appeared to be impaired in the ataxia telangiectasia cells tested with the same defined pattern of MRE11 foci [35,37]. To consolidate the observation of an impairment of the ATM activity in USH1 cells, we investigated the occurrence of MRE11 foci in irradiated USH1 fibroblasts. The MRE11 foci in the radioresistant controls appeared from 2 to $8 \mathrm{~h}$ post-irradiation, and reached their maximal yield at $4 \mathrm{~h}(7 \pm 2 \mathrm{MRE} 11$ foci per cell) (Figure $5 \mathrm{~A}, \mathrm{~B})$. The shape of the MRE11 foci kinetics of the three USH1 fibroblasts appeared to be clearly different from that of the radioresistant controls. The maximal number of MRE11 foci was reached at $10 \mathrm{~min}$ (for GM03889), $1 \mathrm{~h}$ (for GM03891), or $4 \mathrm{~h}$ post-irradiation, but never reached the maximal value assessed in the radioresistant controls. At $4 \mathrm{~h}$ post-irradiation, the values were GM03889: $1 \pm 0.8$, GM03854: $2.2 \pm 1.2$, and GM03891: $1.3 \pm 1.3$ vs. 1BR3: $7 \pm 2, p>0.05$ (Figure 5A). At $24 \mathrm{~h}$ post-irradiation, the number of MRE11 foci was found to be different from zero for the three USH1 cell lines tested, and was higher than for controls, even if this trend was statistically significant only for the GM03854 cells $(p<0.01)$. Altogether, these findings indicate that the USH1 fibroblasts tested elicited an abnormal MRE11 foci formation after radiation. The MRE11 foci kinetics obtained from the HD, TSC, and XPD cells are also shown in Figure 5B. The data obtained from the HD, TSC, and XPD fibroblasts tested showed significantly higher numbers of MRE11 at $1 \mathrm{~h}$ and $4 \mathrm{~h}$ post-irradiation $(p<0.05)$, and a higher number of MRE11 foci at $24 \mathrm{~h}$ post-irradiation $(p<0.1)$, compared to USH1 data, suggesting a different involvement of MRE11 nuclease in the response of USH1 cells to IR than in the other syndromes tested (Figure 4B).

A

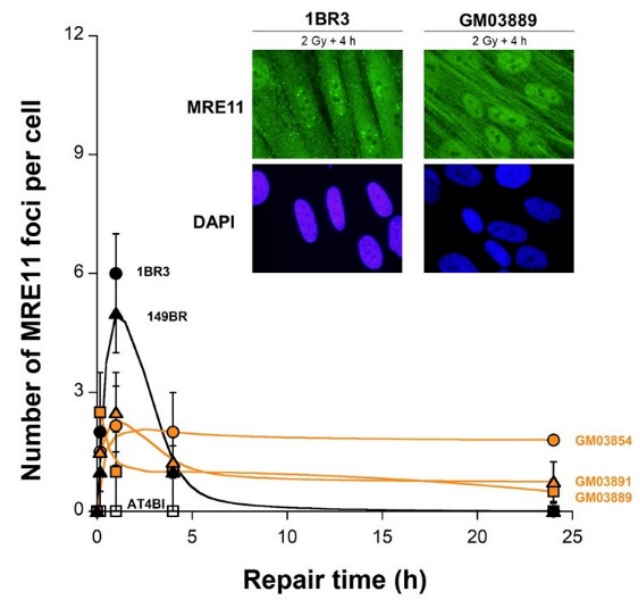

B

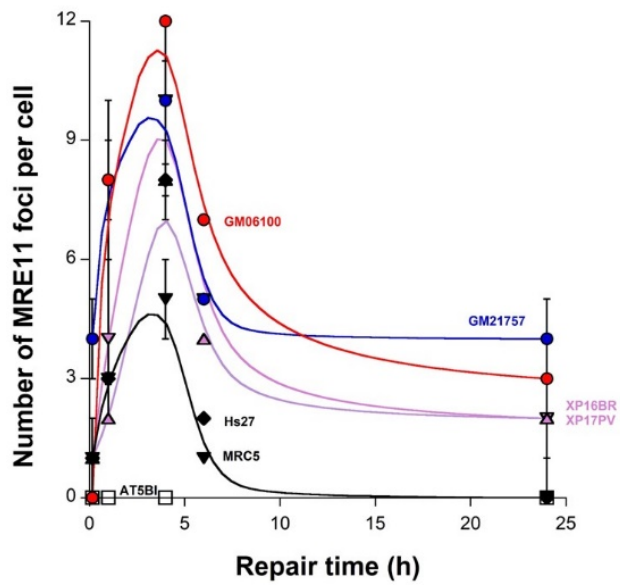

Figure 5. Kinetics of the appearance/disappearance of MRE11 foci in USH1 fibroblasts: The number of MRE11 foci was plotted against post-irradiation time. Data were obtained from the radioresistant controls 1BR3 and 149BR, the hyper-radiosensitive ATM-mutated AT4BI, and the three USH1 (GM03854, GM03889, and GM03891) fibroblast cell lines (A), and from the radioresistant controls MRC5 and Hs27, the hyper-radiosensitive ATM-mutated AT5BI, the HD (GM21757), the TSC (GM06100), and two XPD (XP16BR and XP17PV) fibroblast cell lines (B). Each plot represents the mean \pm SEM of three replicates. Data were fitted to Bodgi's formula [36]. The insert shows a representative illustration of DAPI-stained nuclei and MRE11 foci observed at $4 \mathrm{~h}$ post-irradiation in the indicated cell lines.

It is noteworthy that no correlation was obtained between the SF2 data and the MRE11 data from any of the cell lines tested, whatever the post-irradiation time (data not shown), confirming again that the MRE11 foci are not reliable endpoints for predicting radiosensitivity, as reported previously [37]. 


\subsection{Subcellular Localization and Expression of the USH1 Proteins in USH1 Fibroblasts}

Cellular radiosensitivity has been generally linked to impairment in DSB repair and signaling, associated with dysfunction of proteins that are generally nuclear [25]. To further investigate the role of the USH1 proteins in the molecular response to IR, their subcellular localization was analyzed by applying immunofluorescence as a first step. Because the mutations of USH1B, USH1C, USH1D, and USH1G represent the great majority of USH1 cases (see Section 1), we focused on these four proteins. The radioresistant control fibroblasts showed USH1 protein signals as being essentially localized in the cytoplasm, with the exception of some nuclear forms encountered in USH1C/Harmonin and USH1G/SANS (Figure 6). X-ray irradiation did not change this conclusion, regardless of the repair time investigated. In all of the USH1 fibroblasts tested, the USH1B/MYO7A, USH1C/Harmonin, USH1D/CDH23, and USH1G/SANS proteins appeared to be essentially localized in the cytoplasm before irradiation. Some nuclear forms of USH1C/Harmonin and USH1G/SANS were also observed; again, $\mathrm{X}$-rays did not change the subcellular localization of these proteins in the three USH1 fibroblasts tested (Figure 6). Altogether, these data suggest that all of the USH1 proteins tested are expressed in the cytoplasm of USH1 fibroblasts.

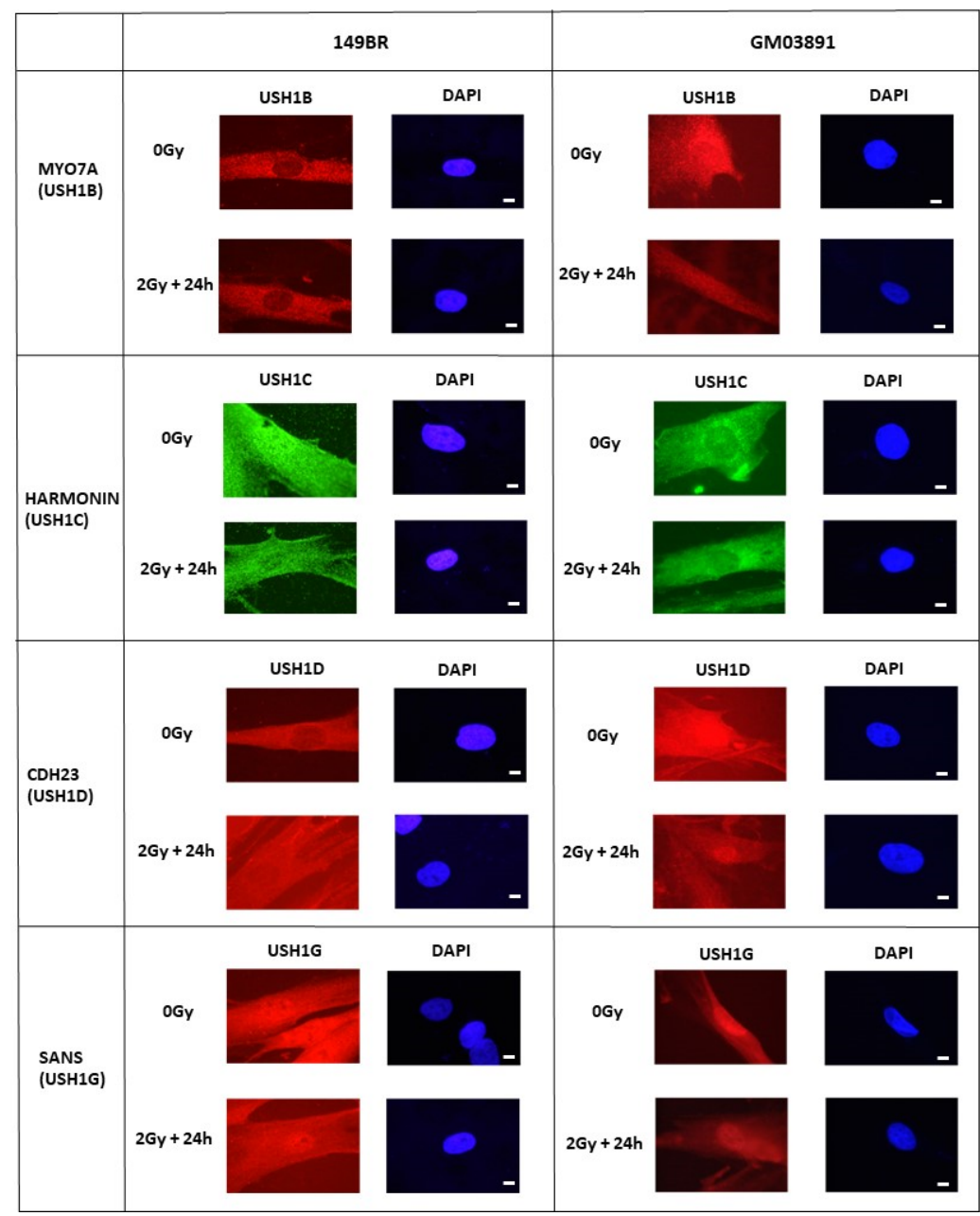

Figure 6. Subcellular localization of USH1 proteins in USH1 and control fibroblasts: AntiUSH1B/MYO7A, anti-USH1D/CDH23, anti-USH1C/Harmonin, and anti-USH1G/SANS immunofluorescence was applied to the radioresistant 149BR controls and the USH1 GM03891 fibroblasts, either before or after irradiation $(2 \mathrm{~Gy}+24 \mathrm{~h})$, as indicated. The white bar represents $5 \mu \mathrm{m}$.

Since simple immunofluorescence analysis does not enable quantitative evaluation of the amount of protein, we examined the expression of the USH1B, USH1C, USH1D, and 
USH1G proteins by using immunoblots. All of the tested USH1 proteins migrated at the expected size in the radioresistant controls and in the USH1 fibroblasts, eliminating the possibility of truncated mutations (Figure 7). The USH1B/MYO7A and USH1G/SANS proteins appeared to be significantly more expressed in USH1 fibroblasts than in radioresistant controls. Immunoblots with cytoplasmic extracts reached similar conclusions, suggesting an overexpression of the USH1B/MYO7A and USH1G/SANS proteins in the cytoplasm of the three USH1 fibroblasts tested (Figure 7 and data not shown). It should be noted that both USH1 GM03889 and GM03891 cells were found to have mutations in the USH1B gene, and no USH1 mutation has yet been identified in USH1 GM03854 cells, but not all of the promoter sequence of USH1B has been investigated (see Section 4).
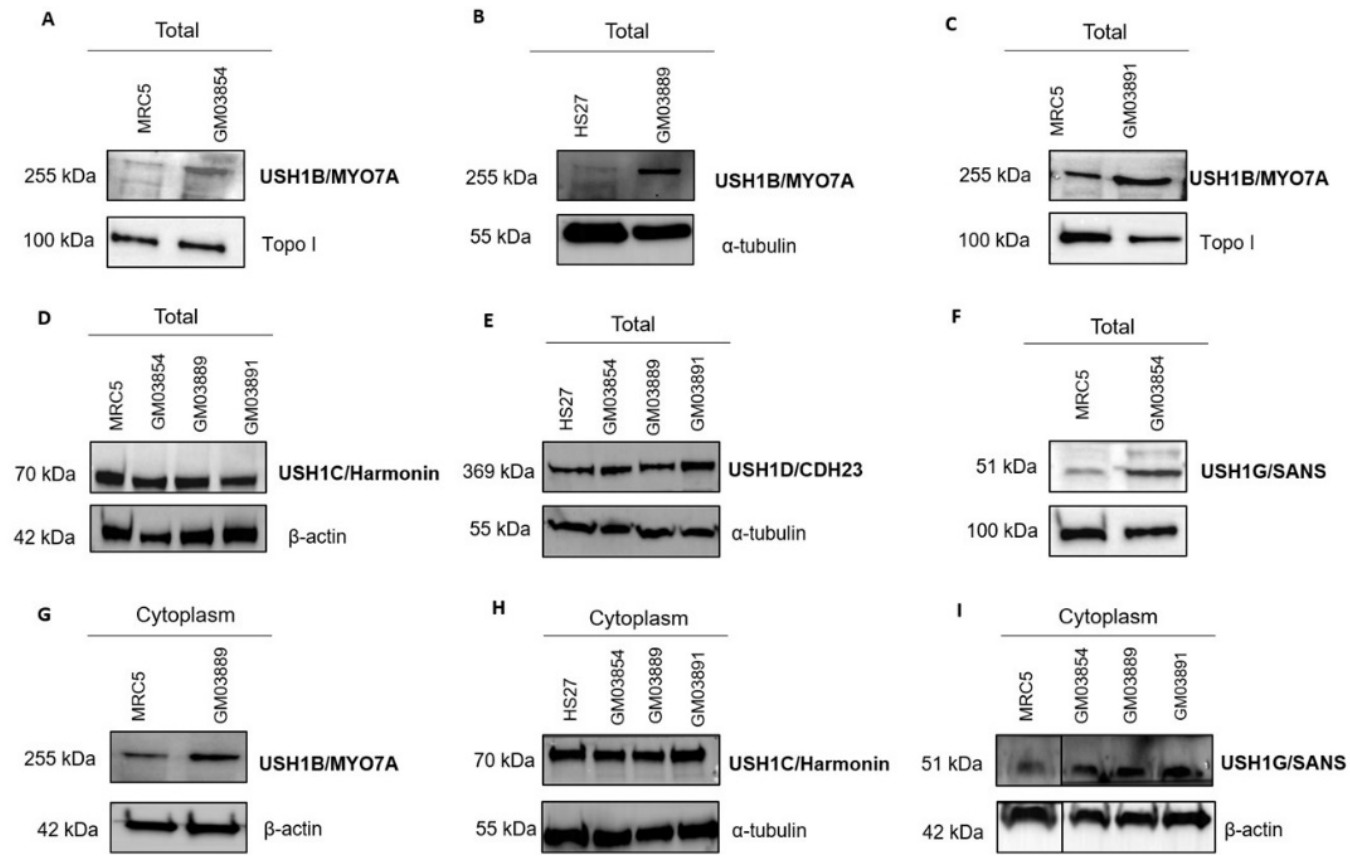

Figure 7. Representative immunoblots of USH1 protein expression in USH1 fibroblasts: A total of $30 \mu \mathrm{g}$ of protein was subjected to SDS/PAGE. Representative immunoblots showing the expression of different USH1 proteins in the indicated radioresistant control and USH1 fibroblasts. Expression of USH1B (A-C), USH1C (D), USH1D (E), and USH1G (F) in total protein extracts. Expression of USH1B (G), USH1C (H), and USH1G/SANS (I) in cytoplasmic protein extracts. It is noteworthy that the blot was cut to provide panel I.

\subsection{Some USH1 Proteins Interact with ATM More Abundantly in USH1 Fibroblasts}

Some USH1 proteins, such as USH1B/MYO7A, hold putative SQ and/or TQ domains of phosphorylation by ATM [38], suggesting that these proteins may interact with ATM and be phosphorylated. Since the RIANS is delayed in the USH1 fibroblasts, and since these USH1 proteins appeared to be overexpressed in the cytoplasm of USH1 fibroblasts, we hypothesized that some USH1-ATM protein complexes may be formed after irradiation, consistent with the delayed RIANS. Similar hypotheses have notably been presented in HD, TSC, NF1, and XPD syndromes [26-29]. We therefore, as a first step, examined the existence of these USH1-ATM complexes in USH1 fibroblasts and their subcellular localization. A proximity ligation assay (PLA) was therefore applied on the three USH1 cell lines tested. The images obtained revealed significant red dots in the cytoplasm of the USH1 cell lines, supporting the existence of cytoplasmic USH1B-ATM, USH1C-ATM, USH1D-ATM, and USH1G-ATM complexes whose abundance changed depending on the USH1 cell line tested. Although some USH1-ATM complexes may be found in the nucleus, depending on the nature of the USH1 protein, the number of the USH1-ATM complexes clearly appeared to be much higher in USH1 cells than in control cells-especially in the cytoplasm (Figure 8). 
Altogether, our findings suggest that ATM binds to some USH1 proteins in the cytoplasm, but to an extent that depends on USH1 individuals.

A

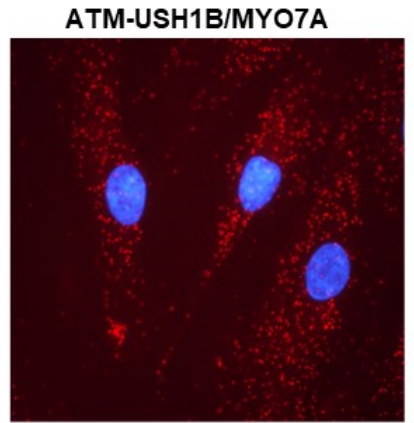

ATM-USH1D/CDH23

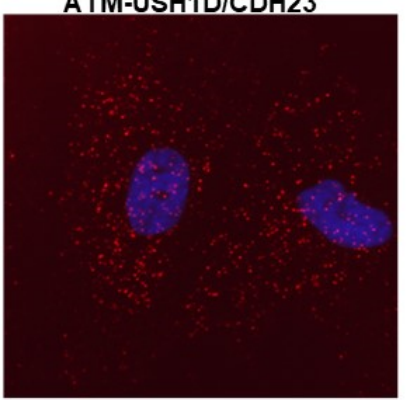

B
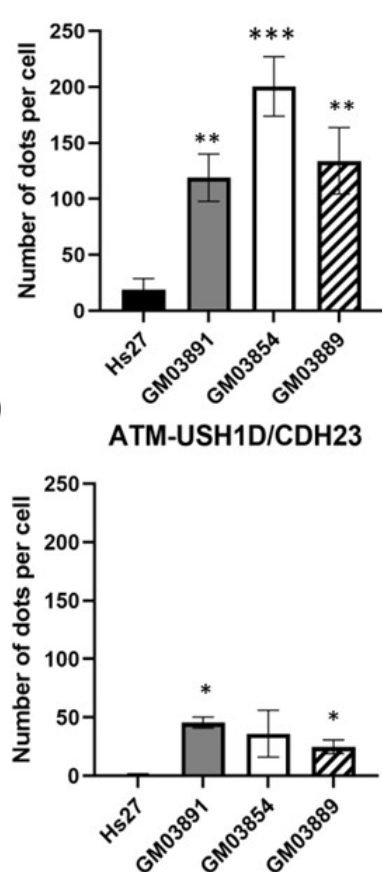

ATM-USH1C/HARMONIN

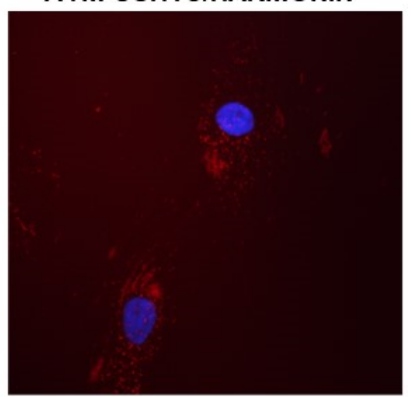

ATM-USH1G/SANS

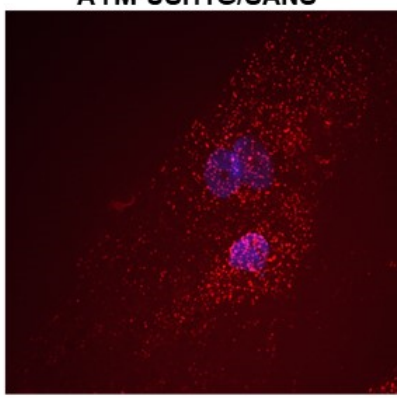

C ATM-USH1C/HARMONIN

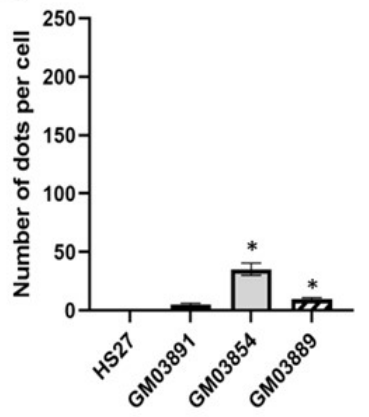

E

ATM-USH1G/SANS

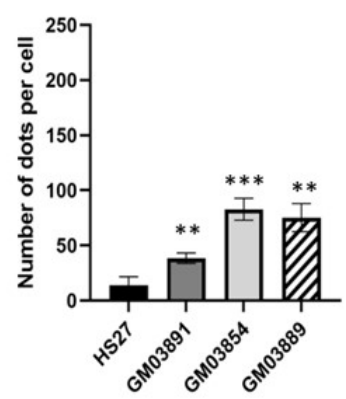

Figure 8. Interaction between ATM and USH1 proteins: A proximity ligation assay (PLA) was applied to the indicated cell lines. Representative PLA images obtained from GM03891 cells (A) Some nuclear PLA signals may be observed, but they do not represent the majority of ATM-USH1 protein complexes. The average numbers of red dots representing the cytoplasmic ATM-USH1 protein complexes were scored per 100 cells (B-E). Each datum represents the mean \pm SEM of at least two independent replicates. The nuclei were counterstained with DAPI (blue). Asterisks represent the statistically significant differences from radioresistant controls, expressed as $p$-values $(1,2$ and 3 asterisks correspond to $p<0.05, p<0.01$, and $p<0.001$, respectively). 


\subsection{Treatment with Statins and Bisphosphonates Protects USH1 Fibroblasts from Radiation}

In previous studies, the combination of pravastatin and zoledronate, known as the ZOPRA treatment, was shown to accelerate the RIANS and to decrease radiosensitivity in a number of genetic diseases, including HD, TSC, NF1, and XPD [26-29]. The choice of these two drugs was motivated by published findings suggesting that the combination of statins and aminobisphosphonates efficiently inhibits both farnesylation and geranylgeranylation of progerin and prelamin A, and markedly improves nuclear abnormalities associated with DNA damage repair and signaling impairments [39]. The ZOPRA treatment did not significantly affect the yields of micronuclei or the kinetics of $\gamma \mathrm{H} 2 \mathrm{AX}, \mathrm{pATM}$, and MRE11 foci in radioresistant control cells (data not shown). With regard to micronuclei, the ZOPRA treatment significantly reduced the yield of micronuclei in USH1 fibroblasts, with the exception of the GM03891 cells (Figure 9A). With regard to the $\gamma \mathrm{H} 2 \mathrm{AX}$ data, the number of $\gamma \mathrm{H} 2 \mathrm{AX}$ foci assessed $10 \mathrm{~min}$ post-irradiation was found to be significantly increased in the GM03889 and GM03891 cells, but not in the GM03954 cells (Figure 9B). With regard to the pATM data, the amount of pATM assessed $10 \mathrm{~min}$ post-irradiation increased in all of the USH1 cells tested, but this trend was not significant in GM03889 cells (Figure 9C). Similarly, with regard to the MRE11 data, the amount of MRE11 assessed at $4 \mathrm{~h}$ post-irradiation increased in all of the USH1 cells tested, but this trend was not significant in GM03891 cells (Figure 9D). Altogether, these data suggest that the ZOPRA treatment may play a role in protecting USH1 fibroblasts against IR by accelerating the RIANS and stimulating the ATM kinase activity in the nucleus. However, the benefit of the treatment may strongly depend on USH1 individuals and molecular endpoints.

\section{A}

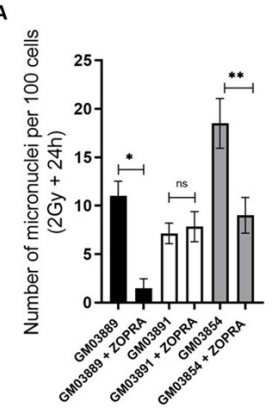

C

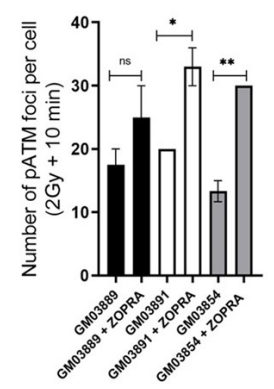

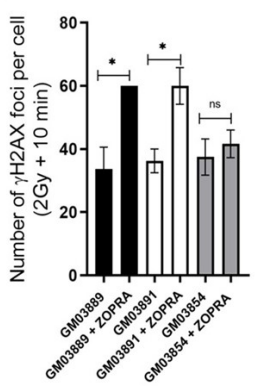

D

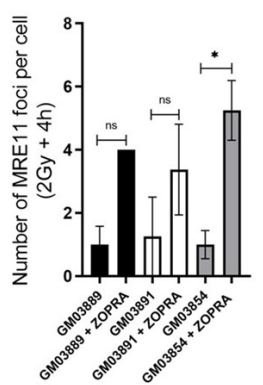

Figure 9. Effect of ZOPRA treatment in USH1 fibroblasts in response to radiation: Numbers of micronuclei per 100 cells assessed after 2 Gy followed by $24 \mathrm{~h}$ post-irradiation (A), numbers of $\gamma \mathrm{H} 2 \mathrm{AX}$ foci per cell assessed after $2 \mathrm{~Gy}$ followed by $10 \mathrm{~min}$ post-irradiation (B), numbers of pATM foci per cell assessed after 2 Gy followed by $10 \mathrm{~min}$ post-irradiation (C), and numbers of MRE11 foci per cell assessed after 2 Gy followed by $4 \mathrm{~h}$ post-irradiation (D) in the GM03889, GM03891, and GM03854 USH1 fibroblasts, with or without ZOPRA treatment. Data points represent the mean \pm SEM of duplicate experiments. Asterisks represent the statistically significant differences from radioresistant controls, expressed as $p$-values ( 1 , and 2 asterisks correspond to $p<0.05$, and $p<0.01$, respectively, ns corresponds to $p>0.1$ ). 


\section{Discussion}

\subsection{The USH1 Fibroblasts Show Significant Molecular and Cellular Radiosensitivity}

The USH1 fibroblasts tested here showed significant radiosensitivity associated with a low SF2 value, a high yield of residual micronuclei, and a significant delay in the RIANS, with abnormal $\gamma \mathrm{H} 2 \mathrm{AX}$, pATM, and MRE11 foci kinetics after irradiation. The ZOPRA data suggest that an acceleration of RIANS may decrease some aspects of the radiosensitivity of USH1, and there is evidence of the existence of abundant USH1-ATM complexes in the cytoplasm of USH1 cells. Hence, the radiosensitivity of USH cells reported in the 1980s [19,20] is confirmed and consolidated by the present study. It must be stressed that the level of this radiosensitivity is among the 10 highest described in humans [24]. However, our findings should be considered at the scale of the number of cases investigated-indeed, even if the different techniques and endpoints independently converge to the same conclusions, we are aware that this report is based on the radiobiological characterization of only three USH1 fibroblast cell lines.

USH1 is the most severe form of USH. It is not possible to clinically discriminate the forms of USH1 caused by the mutations of the different causative USH1 genes. However, the USH1B / MYO7A and USH1D/CDH23 mutations represent $53-73 \%$ and $7-20 \%$ of USH1 cases, respectively [40]. Interestingly, USH1D/CDH23 mutations generally result in truncated proteins (nonsense, frameshift, or splice mutations), while the great majority of USH1B / MYO7A mutations are missense mutations. Furthermore, the USH1C gene is rarely involved in USH1 cases, and no mutation has been identified in the USH1G/SANS gene [40]. As evoked in the Materials and Methods, DNA sequencing confirmed the USH1 status for two (GM03889 and GM03891 cells) of the three USH1 cell lines tested here. Further investigations are needed in order to pursue the DNA sequencing analysis of the GM03854 cells, and to document the genotype-phenotype relationship.

\subsection{USH1 Proteins Interact with ATM in the Cytoplasm and May Influence the RIANS}

The cellular radiosensitivity linked to USH was first observed in the 1980s $[19,20]$. To our knowledge, the present study is one of the first examples of investigations of the molecular and cellular responses of USH1 cells to IR. Our approach was based on the RIANS model that has been successfully validated with a number of other genetic diseases [26,27,29,34,41-43]. The RIANS model is based on three steps: (1) immediately after irradiation, cytoplasmic ATM dimers dissociate in ATM monomers in a linearly dosedependent manner; (2) the resulting ATM monomers diffuse in the nucleus; and (3) the ATM monomers phosphorylate the H2AX molecules around the DSB sites, triggering a cascade of ATM-dependent phosphorylation of ATM substrates, from the recognition of DSBs to their complete repair via the NHEJ pathway [30,44]. When these RI steps are rapid (i.e., less than $10 \mathrm{~min}$ after $2 \mathrm{~Gy} \mathrm{X}$-rays), they lead to a phenotype of radioresistance (called group I). Any delay in the RIANS - especially one caused by the formation of a protein complex with ATM monomers-leads to the impairment of DSB recognition and repair and, therefore, to a phenotype of significant but moderate radiosensitivity (called group II) [44]. In some cases, the DSB recognition (e.g., when ATM is mutated) or the DSB repair step (e.g., when LIG4 is mutated) can be totally prevented, leading to a hyperradiosensitivity phenotype (called group III) corresponding to an SF2 lower than $20 \%$. The group III syndromes are generally caused by the suppression of a biological function caused by homozygous mutations, while group II syndromes are caused by heterozygous mutations [44]. Interestingly, the USH syndrome is a recessive genetic disorder, which may suggest that USH1 syndrome can be classified as a group III disease, but the SF2 values assessed in the present study in the USH1 cells were found to be between 18 and $22 \%$, i.e., corresponding to the cellular radiosensitivity of the genetic diseases belonging to group II of radiosensitivity, such as HD, TSC, NF1, and XPD [26-29]. The tested USH1 fibroblasts also showed a delayed RIANS, likely caused by the existence of cytoplasmic USH1-ATM complexes that may facilitate the sequestration of ATM proteins. A delayed RIANS is a specific feature of group II syndromes (Figure 10). 


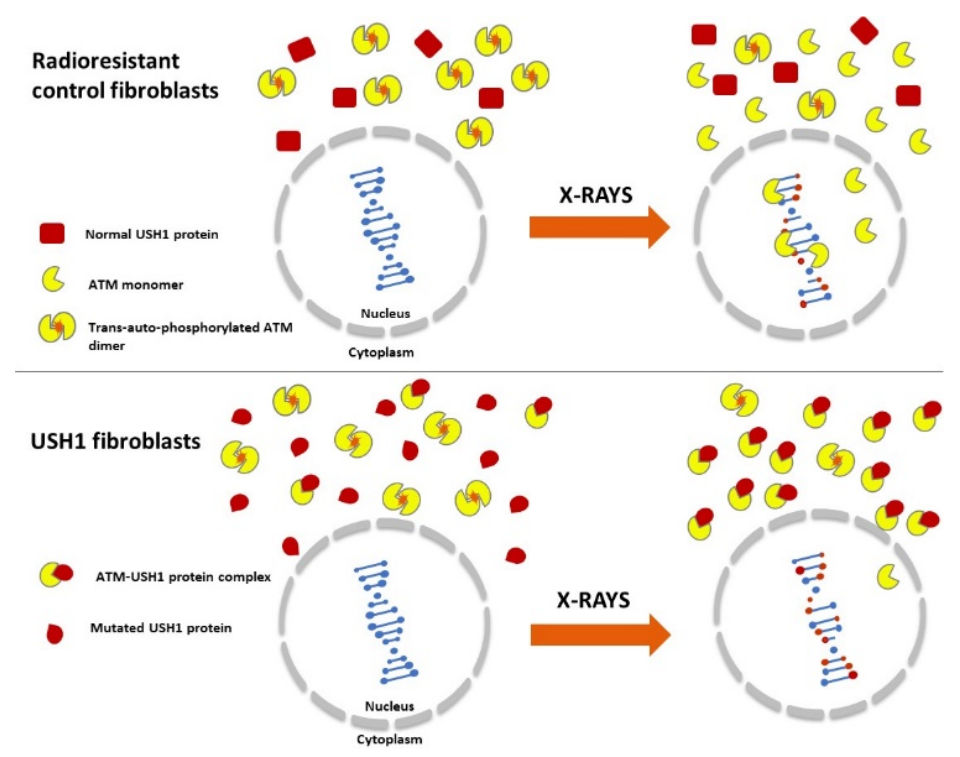

Figure 10. The RIANS model in the USH1 cells: IR induce the monomerization of ATM dimers. The resulting ATM monomers diffuse into the nucleus and participate in DSB recognition via H2AX phosphorylation. In the USH1 cells, USH1 proteins are found to be overexpressed and, as ATM phosphorylation substrates, interact with ATM monomers. The formation of the ATM-USH1 complexes prevents the diffusion of a number of ATM monomers in the nucleus, and delays the ATM nucleo-shuttling, leading to a lack of DSB recognition and to the radiosensitivity phenotype of USH1 cells.

Interestingly, the USH1 proteins are not associated with specific functions in DSB repair and signaling pathways. Moreover, the yields of residual $\gamma \mathrm{H} 2 \mathrm{AX}$ foci reflecting unrepaired DSBs found in the tested USH1 fibroblasts were very low, consistent with the absence of any DSB repair defect. However, there are some emerging links between kinetochore and microtubule proteins and USH proteins, but USH2 rather than USH1 proteins may be required for the control of chromatin integrity and the formation of normal metaphases [45]. Conversely, the DSB recognition, reflected by the yield of early $\gamma \mathrm{H} 2 \mathrm{AX}$ and pATM foci, was found to be impaired, while the great majority of the cells irradiated in these experiments were quiescent. Our findings therefore suggest that USH1 is also required for the very early response to IR, but this step does not concern the formation of mitoses; the potential role of USH1 in mitotic cells, as "protein", cannot be incriminated in the DSB recognition process. In parallel, the present findings and the RIANS model suggest that some mutated USH1 proteins are overexpressed "substrates" of ATM (whose requirement in the DSB recognition process is well documented), and contribute to its sequestration in the cytoplasm (Figure 10). There are numerous analogies with other genetic syndromes such as HD, TSC, NF1, and XPD, characterized by moderate but significant radiosensitivity, delayed RIANS, and significant impairment of DSB recognition but normal DSB repair [26-29]. Like the aforementioned syndromes, USH1 may be associated with mutated protein substrates of ATM that are overexpressed in the cytoplasm [26-29]. However, further investigations are needed in order to better understand the causes of the overexpression of the USH1 proteins found in cells from USH1 patients.

\subsection{USH1 Syndrome, Cancer Proneness, and Aging?}

The radiosensitivity of USH1 cells is among the highest reported in humans. However, radiosensitivity does not necessarily mean cancer proneness. For example, progeroid syndromes are in the top three of human radiosensitivity syndromes, but progeria is associated not with cancer proneness but with aging [37]. Considering the potential role of USH1 proteins in genome maintenance and in cellular scaffold integrity, it is important to discuss these two different clinical features. 
In our results, a drastic increase in the number of MRE11 foci early after irradiation was generally associated with high cancer proneness. This is notably the case of fibroblasts from neurofibromatosis type I patients [28]. Conversely, when the number of MRE11 foci is lower than controls in the first hour post-irradiation, and progressively increases with post-irradiation time to reach its maximal value at $24 \mathrm{~h}$, it is associated with aging and neurodegeneration [34]. Interestingly, the MRE11 response of the three USH1 cell lines tested here was clearly different from that of the controls, but showed a combination of the two trends described above: two USH1 cell lines showed their highest number of MRE11 foci early after irradiation, but without exceeding those of controls; conversely, the three USH1 cell lines showed more delayed MRE11 foci than controls. In our results, these MRE11 data suggest both the presence of some early misrepaired DNA strand breaks that might reflect a cancer-prone hyper-recombination process, and the accumulation of some late DNA strand breaks that are generally associated with an aging phenotype [37]. Interestingly, by focusing on the particular case of the USH1B/MYO7A protein, it appears that its overexpression promotes cellular proliferation and the lack of adhesion between cells. This is notably the case for some melanoma models, in which the overexpression of the USH1B/MYO7A protein facilitates their progression, which may be a link to cancer proneness [46]. In parallel, mutations in the USH1B/MYO7A genes result in the progressive deterioration of hair cells, leading to hearing loss, which may suggest an aging-like process [12]. These two potential consequences of the USH1 mutations may strongly depend on the nature of the mutation and the mutated protein, but overall on the tissue considered. Such duality may be also compared with some group III diseases, such as ataxia telangiectasia, which combine a high risk of lymphoma and an early degeneration of the Purkinje cells or some subset of XPD showing both skin tumors and neurological defects [47]. Again, further investigations are needed in order to better understand the function of USH1 proteins in the radiosensitivity, radiosusceptibility, and radiodegeneration processes, as well as the phenotype-genotype relationship.

\section{Materials and Methods}

\subsection{Cell Lines}

All of the experiments were performed with untransformed fibroblast cells in the plateau phase of growth, under standard culture conditions described elsewhere [30,48]. All of the fibroblast cell lines used in this study were purchased from commercial repositories. Four radioresistant (1BR3, 149BR, MRC5, and Hs27) controls originating from apparently healthy patients, two hyper-radiosensitive ataxia telangiectasia (ATM-mutated; AT4BI and AT5BI), one Huntington's disease (HD) (GM21757), one tuberous sclerosis syndrome (TSC) (GM06100), two xeroderma pigmentosum D (XPD) (XP16BR and XP17PV), and three USH1 (GM03889, GM03891, and GM03854) fibroblast cell lines were used in this study. The radiobiological features of the non-USH1 cells have been detailed and published elsewhere [26-30,48]. The three USH1 (GM03889, GM03891, and GM03854) fibroblast cell lines were purchased from Coriell Cell Repositories (Camden, NJ, USA). All of these cell lines were derived from male USH1 patients. The age at sampling of the corresponding USH donors was 22, 16, and 47, respectively. With regard to their clinical features provided by the Coriell Institute, both the GM03889 and GM03891 donors suffered from tapetoretinal degeneration, while the GM03854 donor was mildly affected with a slow progression of RP.

\subsection{DNA Extraction and MYO7A Sequencing}

DNA was extracted using the QIAamp DNA Micro Kit (\#56304, QIAGEN, Hilden, Germany). The coding exons and flanking intronic sequences of MYO7A were amplified and sequenced using forward and reverse primers designed using Primer3 (v.0.4.0). Primer sequences and conditions are available upon request. The following primer sequences were used for the amplification of exons 14 (MYO7A_EX14F and MYO7A_EX14R) and 40, (MYO7A_EX40F and MYO7A_EX40R), respectively: GTAGTTCCAATTCATCCACTTAAC, ATGCACAGCACTGTGAAGTACTTAG, AGGTCCTGTGACTCCCGATG, and AGGGGCT- 
CATCCCACAAG, respectively. Sequences were run on an ABI3730 DNA analyzer, and assembled using ABI Prism SeqScape 3.0 from the GenBank reference sequence. Two USH1B/MYO7A mutations were detected in GM03889 and GM03891 cells: the 1555-8C > G splice site variant on intron 13 (p.([Gly519Serfs*27,Gly519Alafs*58]). rs1057517774), which has been previously reported in association with USH1 [49], and the 5515_5522dup variant on exon 40 (p.(Gly1842Cysfs*40). rs762117246), which has only been reported in the deafness variation database. Concerning the GM03854 cells, no mutation was detected in the USH1B/MYO7A, USH1C/Harmonin, or USH1D/CDH23 gene sequences.

\subsection{X-ray Irradiation}

Irradiations was performed with a $6 \mathrm{MeV}$ X-ray medical irradiator (SL 15 Philips) (dose rate: 6 Gy.min ${ }^{-1}$ ) at the Centre Léon-Bérard (Lyon, France) [30,48]. In all of the experiments, a dose of 2 Gy was chosen because it simulates a current dose per session in standard radiotherapy.

\subsection{Zoledronate and Pravastatin Treatment (ZOPRA)}

The combination (ZOPRA) of an anti-osteoporosis bisphosphonate (zoledronate) and an anti-cholesterolemic statin (pravastatin) has been shown to accelerate the RIANS [39]. The ZOPRA treatment was applied under conditions that are described elsewhere. Briefly, cells were incubated with $1 \mu \mathrm{M}$ pravastatin (\#P4498, Sigma-Aldrich France, Saint-QuentinFallavier, France) in phosphate-buffered saline (PBS) (\#14040-091, Sigma-Aldrich) for $24 \mathrm{~h}$ at $37^{\circ} \mathrm{C}$. Thereafter, $1 \mu \mathrm{M}$ zoledronate (\#SML0223, Sigma-Aldrich) in PBS was added to the culture medium, and cells were incubated for $12 \mathrm{~h}$ at $37^{\circ} \mathrm{C}$ [39].

\subsection{Clonogenic Cell Survival}

The intrinsic cellular radiosensitivity was quantified from clonogenic cell survival data obtained from standard delayed plating procedures that are described elsewhere [50]. Cells in the plateau phase of growth were irradiated at the indicated doses, incubated for $24 \mathrm{~h}$ at $37^{\circ} \mathrm{C}$, and then harvested, counted using a hemocytometer (Kisker Biotech $\mathrm{GmbH}$ \& Co, Steinfurt, Germany), and diluted to a predefined number of cells (between 100 and 1000 cells) to be seeded in $10 \mathrm{~cm}$ Petri dishes. After 15 days at $37^{\circ} \mathrm{C}$ in a $\mathrm{CO}_{2}$ incubator, cells were washed with PBS (Sigma-Aldrich) and stained for $1 \mathrm{~min}$ in crystal violet solution (75\% ethanol 95\%, 25\% crystal violet \#HT90132, Sigma-Aldrich). After a final wash with water, only the colonies with more than 50 cells were scored. The survival data were fitted to the linear quadratic (LQ) model that describes the cell survival $S$ as a function of dose D as follows: $S=e^{-\left(\alpha D+\beta D^{2}\right)}$, where $\alpha$ and $\beta$ are adjustable parameters to be determined. The intrinsic radiosensitivity was quantified by calculating the surviving fraction at $2 \mathrm{~Gy}$ (SF2) [44].

\subsection{Immunofluorescence}

The immunofluorescence protocol and nuclear protein foci scoring are described elsewhere $[29,30]$. Four antibodies against USH1 proteins were used at 1:100: the polyclonal anti-rabbit anti-cadherin like 23 (\#ab131135), the monoclonal anti-rabbit anti-myosin VII A (\#ab150386), the polyclonal anti-rabbit anti-USH1G (\#ab150820), and the monoclonal antiUSH1C (\#ab56812), all from Abcam (Cambridge, UK). Anti- $\gamma H 2 A X^{\text {ser139 }}$ antibody (\#05-636; Merck Millipore, Burlington, VT, USA) was used at 1:800. The monoclonal anti-mouse anti-MRE11 (\#56211) from QED Bioscience (San Diego, CA, USA) and the monoclonal antimouse anti-pATM ${ }^{\text {ser1981 }}$ (\#05-740) from Merck Millipore were used at 1:100. Incubations with anti-mouse fluorescein (FITC) and rhodamine (TRITC) secondary antibodies were performed at $1: 100$ at $37^{\circ} \mathrm{C}$ for $20 \mathrm{~min}$. Slides were mounted in $4^{\prime}, 6^{\prime}$ diamidino-2-phenylindole (DAPI)-stained VECTASHIELD (CliniSciences, Nanterre, France) and examined with an Olympus BX51 fluorescence microscope. 


\subsection{Proximity Ligation Assay}

The proximity ligation assay (PLA) is a specific immunofluorescence technique that allows visualization of endogenous protein-protein interactions at the single molecule level [51]. Briefly, cells were plated on glass coverslips until reaching a minimum of $70 \%$ confluency. Cells were then fixed in $4 \%(w / v)$ paraformaldehyde for $15 \mathrm{~min}$ at room temperature, and were permeabilized in $0.5 \%$ Triton $\mathrm{X}-100$ solution for $3 \mathrm{~min}$ at $4{ }^{\circ} \mathrm{C}$. Cells were then blocked for $2 \mathrm{~h}$ at room temperature using $30 \mu \mathrm{L}$ of blocking solution from the Duolink $^{\mathrm{TM}}$ In Situ Orange Starter Kit Mouse/Rabbit (\#DUO92102, Sigma-Aldrich) per cover slip. Mixtures of two primary antibodies' incubations were performed for $1 \mathrm{~h}$ at $37^{\circ} \mathrm{C}$. The following antibodies were all diluted in the Duolink antibody diluent 1X (\#DUO82008, Sigma-Aldrich) at a ratio of 1:100: mouse monoclonal antibody (2C1 (1A1)) anti-ATM (\#ab78), rabbit monoclonal (EPR7497), anti-Myosin VIIa/MYO7A (\#ab150386), rabbit polyclonal anti-cadherin like 23 (\#ab192498-Abcam), rabbit polyclonal anti-USH1G (\#ab150820), and rabbit monoclonal anti-USH1C/Harmonin (\#ab133763) from Abcam. PLA probes (Duolink PLA Probe anti-mouse MINUS \#DUO82004-100RXN, Lot \#SLCD468 and Duolink PLA Probe anti-rabbit PLUS \#DUO82002-100RXN, Lot \#SLLC564 from Sigma-Aldrich) were diluted using Duolink antibody diluent at a 1:5 ratio, and cells were incubated with the probes for $1 \mathrm{~h}$ at $37^{\circ} \mathrm{C}$ in a humidified chamber. After $1 \mathrm{~h}$ of incubation, cells were washed with Wash Buffer A (\#DUO82046-1EA; Sigma-Aldrich). Cells were then incubated with the ligation solution from the kit for $30 \mathrm{~min}$ at $37^{\circ} \mathrm{C}$ in the humidified chamber, and then washed once more with Wash Buffer A. Cells were incubated with the amplification solution from the kit for $100 \mathrm{~min}$ at $37^{\circ} \mathrm{C}$ in darkness and in the humidified chamber. Cells were then washed with Wash Buffer B (\#DUO82048-1EA, Sigma-Aldrich), followed by a quick wash with 1/100 Wash Buffer B. Samples were mounted with Duolink In Situ Mounting Medium with DAPI (\#DUO82040-Sigma-Aldrich), and subsequently analyzed under fluorescent microscopy. Fluorescent images were viewed under an Olympus BX51 microscope. Analysis and quantification of these samples were performed using ImageJ software. PLA dots were quantified on 16-bit images using the "Analyze Particles" command.

\subsection{Cell Extracts and Immunoblots}

Total extracts were obtained from cells with the following lysis buffer-50 mM Tris, pH 8, $150 \mathrm{mM} \mathrm{NaCl}, 2$ mM EDTA, pH 8, 10\% glycerol, 0.2\% Nonidet NP40 - and applied for $20 \mathrm{~min}$ at $4{ }^{\circ} \mathrm{C}$. Cytoplasmic extracts were obtained from cells using the following buffer$10 \mathrm{mM}$ HEPES pH 7.9, $1.5 \mathrm{mM} \mathrm{MgCl2}, 10 \mathrm{mM} \mathrm{KCL}, 2 \mathrm{mM}$ ethylenediaminetetraacetic acid (EDTA) pH 8, $0.5 \mathrm{mM}$ dithiothreitol (DTT), 0.2\% Nonidet NP40, $\mathrm{H}_{2} \mathrm{O}$ ) —applied for $15 \mathrm{~min}$ at $4{ }^{\circ} \mathrm{C}$. Both buffers were supplemented with protease and phosphatase inhibitors (\#78442, Thermo Fisher, Waltham, USA). Protein concentrations were measured with the Bio-Rad Bradford assay (Bio-Rad Laboratories, Hercules, CA, USA), and aliquots of extracts were stored at $-20^{\circ} \mathrm{C}$. Proteins were subjected to SDS-polyacrylamide gel electrophoresis (SDS-PAGE) and blotted onto polyvinylidene fluoride (PVDF) membranes (Immobilon-P, Millipore). Membranes were blocked in Tris-buffered saline (TBS) solution containing $0.05 \%$ Tween 20 and 5\% (w/v) non-fat dried skimmed milk powder, and incubated with primary antibodies for $3 \mathrm{~h}$ and with horseradish-peroxidase-conjugated secondary antibodies (Jackson ImmunoResearch, West Grove, PA, USA) for $1 \mathrm{~h}$. Antibody binding was determined using the Clarity Max ECL substrate (\#1705061, Bio-Rad Laboratories) and/or the SuperSignal West Femto Maximum Sensitivity Substrate (\#34095, Thermo Scientific, Waltham, MA, USA). Western blot bands were analyzed using Image Lab software (Bio-Rad Laboratories, Hercules, CA, USA).

\subsection{Statistical Analysis}

The immunofluorescence data were fitted to the so-called Bodgi's formula, which describes the kinetics for appearance/disappearance of nuclear foci formed by some protein relocalization after genotoxic stress [36]. Statistical analysis was performed by using 
KaleidaGraph v4 (Synergy Software, Reading, PA, USA) and GraphPad Prism (San Diego, CA, USA).

\section{Conclusions}

The USH1 syndrome appears to be a rare genetic syndrome associated with moderate but significant radiosensitivity, high yields of micronuclei, impaired DSB recognition but normal DSB repair, and delayed RIANS. This latter radiobiological feature is probably due to a facilitated interaction between ATM and the USH1 proteins-especially UHS1B/MYO7A - that are overexpressed in the cytoplasm in skin fibroblasts from USH1 patients (Figure 10).

Supplementary Materials: The following supporting information can be downloaded at https: //www.mdpi.com/article/10.3390/ijms23031570/s1.

Author Contributions: The authors of this manuscript have contributed in the following manners: Conceptualization, J.A.-C., E.B., N.F. and M.M.; data acquisition and methodology, J.A.-C., M.L.F., L.S., A.G., L.E.-N. and M.M.; data analysis, J.A.-C., E.B. and N.F.; writing-original draft preparation, J.A.-C., E.B. and N.F.; writing — review and editing, all authors; project administration and funding acquisition, N.F. All authors have read and agreed to the published version of the manuscript. All authors have approved the submitted version of this manuscript and agreed to be personally accountable for their individual contributions and for ensuring that questions related to the accuracy or integrity of the work are appropriately investigated, resolved, and documented in the literature.

Funding: This work was supported by the Commissariat General à l'Investissement (Programmes Investissement d'avenir - projet INDIRA), the Association Pour la Recherche sur l'Ataxie-Telangiectasie (APRAT), and the National Space Agency (CNES).

Institutional Review Board Statement: All of the fibroblast cell lines used in this study were purchased from commercial repositories (see Section 4).

Informed Consent Statement: The commercial repositories that provided the fibroblast cell lines used in this study applied all of the necessary ethics and regulations related to human sampling (informed and written consent, anonymization, and acceptance for publication).

Data Availability Statement: All of the data used in this work can be provided upon reasonable request.

Acknowledgments: We thank Crystel Bonnet (Institut Pasteur, Institut de l'Audition, Paris, France) and Isabelle Audo (Institut de la Vision, Paris, France) for their help and their technical assistance.

Conflicts of Interest: The authors declare no conflict of interest. The funders had no role in the design of the study; in the collection, analyses, or interpretation of data; in the writing of the manuscript, or in the decision to publish the results.

\section{References}

1. Whatley, M.; Francis, A.; Ng, Z.Y.; Khoh, X.E.; Atlas, M.D.; Dilley, R.J.; Wong, E.Y.M. Usher Syndrome: Genetics and Molecular Links of Hearing Loss and Directions for Therapy. Front. Genet. 2020, 11, 565216. [CrossRef] [PubMed]

2. De Joya, E.M.; Colbert, B.M.; Tang, P.C.; Lam, B.L.; Yang, J.; Blanton, S.H.; Dykxhoorn, D.M.; Liu, X. Usher Syndrome in the Inner Ear: Etiologies and Advances in Gene Therapy. Int. J. Mol. Sci. 2021, 22, 3910. [CrossRef] [PubMed]

3. von Graefe, A. Vereinzelte Beobachtungen und Bemerkungen Exceptionelle Verhalten des Gesichtsfeldes bei Pigmentenartung des Netzhaut. Arch. Klin. Ophthalmol. 1858, 4, 250-253.

4. Ravin, J.G.; Kenyon, C. From von Graefe's clinic to the Ecole des Beaux-Arts. The meteoric career of Richard Liebreich. Surv. Ophthalmol. 1992, 37, 221-228. [CrossRef]

5. Leibreich, R. Abkunft und Eben unter Blutsverwandten als Grund von Retinitis Pigmentosa. Deutsch Klin. 1861, 13, 53-55.

6. Usher, C. On the inheritance of retinitis pigmentosa with notes of cases. R. Lond. Ophthalmol. Hosp. Rep. 1914, 19, 130-236.

7. Boughman, J.A.; Vernon, M.; Shaver, K.A. Usher syndrome: Definition and estimate of prevalence from two high-risk populations. J. Chronic Dis. 1983, 36, 595-603. [CrossRef]

8. Yoshimura, H.; Miyagawa, M.; Kumakawa, K.; Nishio, S.Y.; Usami, S. Frequency of Usher syndrome type 1 in deaf children by massively parallel DNA sequencing. J. Hum. Genet. 2016, 61, 419-422. [CrossRef]

9. Adato, A.; Michel, V.; Kikkawa, Y.; Reiners, J.; Alagramam, K.N.; Weil, D.; Yonekawa, H.; Wolfrum, U.; El-Amraoui, A.; Petit, C. Interactions in the network of Usher syndrome type 1 proteins. Hum. Mol. Genet. 2005, 14, 347-356. [CrossRef]

10. Petit, C. Usher syndrome: From genetics to pathogenesis. Annu. Rev. Genom. Hum. Genet. 2001, 2, 271-297. [CrossRef] 
11. Cosgrove, D.; Zallocchi, M. Usher protein functions in hair cells and photoreceptors. Int. J. Biochem. Cell Biol. 2014, 46, 80-89. [CrossRef] [PubMed]

12. Mathur, P.; Yang, J. Usher syndrome: Hearing loss, retinal degeneration and associated abnormalities. Biochim. Biophys. Acta 2015, 1852, 406-420. [CrossRef] [PubMed]

13. Williams, D.S.; Lopes, V.S. The many different cellular functions of MYO7A in the retina. Biochem. Soc. Trans. 2011, 39, 1207-1210. [CrossRef] [PubMed]

14. Reiners, J.; van Wijk, E.; Marker, T.; Zimmermann, U.; Jurgens, K.; te Brinke, H.; Overlack, N.; Roepman, R.; Knipper, M.; Kremer, H.; et al. Scaffold protein harmonin (USH1C) provides molecular links between Usher syndrome type 1 and type 2. Hum. Mol. Genet. 2005, 14, 3933-3943. [CrossRef]

15. Vanniya, S.P.; Srisailapathy, C.R.S.; Kunka Mohanram, R. The tip link protein Cadherin-23: From Hearing Loss to Cancer. Pharmacol. Res. 2018, 130, 25-35. [CrossRef]

16. Choudhary, D.; Narui, Y.; Neel, B.L.; Wimalasena, L.N.; Klanseck, C.F.; De-la-Torre, P.; Chen, C.; Araya-Secchi, R.; Tamilselvan, E.; Sotomayor, M. Structural determinants of protocadherin-15 mechanics and function in hearing and balance perception. Proc. Natl. Acad. Sci. USA 2020, 117, 24837-24848. [CrossRef]

17. Weil, D.; El-Amraoui, A.; Masmoudi, S.; Mustapha, M.; Kikkawa, Y.; Laine, S.; Delmaghani, S.; Adato, A.; Nadifi, S.; Zina, Z.B.; et al. Usher syndrome type I G (USH1G) is caused by mutations in the gene encoding SANS, a protein that associates with the USH1C protein, harmonin. Hum. Mol. Genet. 2003, 12, 463-471. [CrossRef]

18. Gerber, S.; Bonneau, D.; Gilbert, B.; Munnich, A.; Dufier, J.L.; Rozet, J.M.; Kaplan, J. USH1A: Chronicle of a slow death. Am. J. Hum. genetics 2006, 78, 357-359. [CrossRef]

19. Nove, J.; Tarone, R.E.; Little, J.B.; Robbins, J.H. Radiation sensitivity of fibroblast strains from patients with Usher's syndrome, Duchenne muscular dystrophy, and Huntington's disease. Mutat. Res. 1987, 184, 29-38. [CrossRef]

20. Robbins, J.H.; Scudiero, D.A.; Otsuka, F.; Tarone, R.E.; Brumback, R.A.; Wirtschafter, J.D.; Polinsky, R.J.; Barrett, S.F.; Moshell, A.N.; Scarpinato, R.G.; et al. Hypersensitivity to DNA-damaging agents in cultured cells from patients with Usher's syndrome and Duchenne muscular dystrophy. J. Neurol. Neurosurg. Psychiatry 1984, 47, 391-398. [CrossRef]

21. Gunduz, K.; Shields, J.A.; Shields, C.L.; Zhao, D.Y. Choroidal melanoma in a patient with retinitis pigmentosa and Usher's syndrome. Br. J. Ophthalmol. 1998, 82, 847-848. [CrossRef] [PubMed]

22. Helsloot, L.; Reynders, D.; Cools, P.; Wauters, J. Adenocarcinoma of the Rectum in a 27-year-old Patient with Usher Syndrome: Is there a Genetic Correlation? Acta Gastroenterol. Belg. 2017, 80, 77-78. [PubMed]

23. Tsvetkov, E.A. Senear-Usher syndrome as a complication of radiotherapy of laryngeal cancer. Med. Radiol. 1983, $28,76-77$.

24. Deschavanne, P.J.; Fertil, B. A review of human cell radiosensitivity in vitro. Int. J. Radiat. Oncol. Biol. Phys. 1996, 34, 251-266. [CrossRef]

25. Foray, N.; Bourguignon, M.; Hamada, N. Individual response to ionizing radiation. Mutat. Res. Rev. 2016, 770, 369-386. [CrossRef] [PubMed]

26. Ferlazzo, M.L.; Sonzogni, L.; Granzotto, A.; Bodgi, L.; Lartin, O.; Devic, C.; Vogin, G.; Pereira, S.; Foray, N. Mutations of the Huntington's Disease Protein Impact on the ATM-Dependent Signaling and Repair Pathways of the Radiation-Induced DNA Double-Strand Breaks: Corrective Effect of Statins and Bisphosphonates. Mol. Neurobiol. 2014, 49, 1200-1211. [CrossRef] [PubMed]

27. Ferlazzo, M.L.; Bach-Tobdji, M.K.E.; Djerad, A.; Sonzogni, L.; Burlet, S.F.; Devic, C.; Granzotto, A.; Bodgi, L.; Djeffal-Kerrar, A.; Foray, N. Radiobiological characterization of tuberous sclerosis: A delay in the nucleo-shuttling of ATM may be responsible for radiosensitivity. Mol. Neurobiol. 2017, 55, 4973-4983. [CrossRef] [PubMed]

28. Combemale, P.; Sonzogni, L.; Devic1, C.; Bencokova, Z.; Ferlazzo, M.L.; Granzotto, A.; Burlet, S.F.; Pinson, S.; Amini-Adle, M.; Al-Choboq, J.; et al. Individual response to radiation of individuals with neurofibromatosis type I: Role of the ATM protein and influence of statins and bisphosphonates. Mol. Neurobiol. 2022, 59, 556-573. [CrossRef]

29. Ferlazzo, M.; Berthel, E.; Granzotto, A.; Devic, C.; Sonzogni, L.; Bachelet, J.T.; Pereira, S.; Bourguignon, M.; Sarasin, A.; Mezzina, M.; et al. Some mutations in the xeroderma pigmentosum D gene may lead to moderate but significant radiosensitivity associated with a delayed radiation-induced ATM nuclear localization. Int. J. Radiat. Biol. 2020, 96, 394-410. [CrossRef]

30. Granzotto, A.; Benadjaoud, M.A.; Vogin, G.; Devic, C.; Ferlazzo, M.L.; Bodgi, L.; Pereira, S.; Sonzogni, L.; Forcheron, F.; Viau, M.; et al. Influence of Nucleoshuttling of the ATM Protein in the Healthy Tissues Response to Radiation Therapy: Toward a Molecular Classification of Human Radiosensitivity. Int. J. Radiat. Oncol. Biol. Phys. 2016, 94, 450-460. [CrossRef]

31. Belkacemi, Y.; Colson-Durand, L.; Granzotto, A.; Husheng, S.; To, N.H.; Majdoul, S.; Guet, S.; Herve, M.L.; Fonteneau, G.; Diana, C.; et al. The Henri Mondor Procedure of Morbidity and Mortality Review Meetings: Prospective Registration of Clinical, Dosimetric, and Individual Radiosensitivity Data of Patients with Severe Radiation Toxicity. Int. J. Radiat. Oncol. Biol. Phys. 2016, 96, 629-636. [CrossRef] [PubMed]

32. Pereira, S.; Bodgi, L.; Duclos, M.; Canet, A.; Ferlazzo, M.L.; Devic, C.; Granzotto, A.; Deneuve, S.; Vogin, G.; Foray, N. Fast and binary assay for predicting radiosensitivity based on the nucleoshuttling of ATM protein: Development, validation and performances. Int. J. Radiat. Oncol. Biol. Phys. 2018, 100, 353-360. [CrossRef] [PubMed]

33. Vogin, G.; Bastogne, T.; Bodgi, L.; Gillet-Daubin, J.; Canet, A.; Pereira, S.; Foray, N. The Phosphorylated ATM Immunofluorescence Assay: A High-performance Radiosensitivity Assay to Predict Postradiation Therapy Overreactions. Int. J. Radiat. Oncol. Biol. Phys. 2018, 101, 690-693. [CrossRef] [PubMed] 
34. Berthel, E.; Foray, N.; Ferlazzo, M.L. The Nucleoshuttling of the ATM Protein: A Unified Model to Describe the Individual Response to High- and Low-Dose of Radiation? Cancers 2019, 11, 905. [CrossRef] [PubMed]

35. Joubert, A.; Zimmerman, K.M.; Bencokova, Z.; Gastaldo, J.; Rénier, W.; Chavaudra, N.; Favaudon, V.; Arlett, C.; Foray, N. DNA double-strand break repair defects in syndromes associated with acute radiation response: At least two different assays to predict intrinsic radiosensitivity? Int. J. Radiat. Biol. 2008, 84, 1-19. [CrossRef] [PubMed]

36. Bodgi, L.; Granzotto, A.; Devic, C.; Vogin, G.; Lesne, A.; Bottollier-Depois, J.F.; Victor, J.M.; Maalouf, M.; Fares, G.; Foray, N. A single formula to describe radiation-induced protein relocalization: Towards a mathematical definition of individual radiosensitivity. J. Theor. Biol. 2013, 333, 135-145. [CrossRef]

37. El-Nachef, L.; Al-Choboq, J.; Restier-Verlet, J.; Granzotto, A.; Berthel, E.; Sonzogni, L.; Ferlazzo, M.L.; Bouchet, A.; Leblond, P.; Combemale, P.; et al. Human Radiosensitivity and Radiosusceptibility: What Are the Differences? Int. J. Mol. Sci. 2021, 22, 7158. [CrossRef]

38. Kim, S.T.; Lim, D.S.; Canman, C.E.; Kastan, M.B. Substrate specificities and identification of putative substrates of ATM kinase family members. J. Biol. Chem. 1999, 274, 37538-37543. [CrossRef]

39. Varela, I.; Pereira, S.; Ugalde, A.P.; Navarro, C.L.; Suarez, M.F.; Cau, P.; Cadinanos, J.; Osorio, F.G.; Foray, N.; Cobo, J.; et al. Combined treatment with statins and aminobisphosphonates extends longevity in a mouse model of human premature aging. Nat. Med. 2008, 14, 767-772. [CrossRef]

40. Bonnet, C.; Riahi, Z.; Chantot-Bastaraud, S.; Smagghe, L.; Letexier, M.; Marcaillou, C.; Lefevre, G.M.; Hardelin, J.P.; El-Amraoui, A.; Singh-Estivalet, A.; et al. An innovative strategy for the molecular diagnosis of Usher syndrome identifies causal biallelic mutations in 93\% of European patients. Eur. J. Hum. Genet. EJHG 2016, 24, 1730-1738. [CrossRef]

41. Moulay Lakhdar, I.; Ferlazzo, M.L.; Al Choboq, J.; Berthel, E.; Sonzogni, L.; Devic, C.; Granzotto, A.; Thariat, J.; Foray, N Fibroblasts from Retinoblastoma Patients Show Radiosensitivity Linked to Abnormal Localization of the ATM Protein. Curr. Eye Res. 2021, 46, 546-557. [CrossRef] [PubMed]

42. Bachelet, J.T.; Granzotto, A.; Ferlazzo, M.; Sonzogni, L.; Berthel, E.C.D.; Foray, N. First Radiobiological Characterization of Skin and Bone Cells from A Patient Suffering from the PI3KCA-Related Overgrowth Spectrum (PROS) Syndrome. Arch. Med Clin. Case Rep. 2020, 4, 1052-1066. [CrossRef]

43. Bachelet, J.T.; Granzotto, A.; Ferlazzo, M.; Sonzogni, L.; Berthel, E.; Devic, C.; Foray, N. First radiobiological characterization of the McCune-Albright syndrome: Influence of the ATM protein and effect of statins + bisphosphonates treatment. Int. J. Radiat. Biol. 2021, 97, 317-328. [CrossRef] [PubMed]

44. Bodgi, L.; Foray, N. The nucleo-shuttling of the ATM protein as a basis for a novel theory of radiation response: Resolution of the linear-quadratic model. Int. J. Radiat. Biol. 2016, 92, 117-131. [CrossRef] [PubMed]

45. Kersten, F.F.; van Wijk, E.; Hetterschijt, L.; Baubeta, K.; Peters, T.A.; Aslanyan, M.G.; van der Zwaag, B.; Wolfrum, U.; Keunen, J.E.; Roepman, R.; et al. The mitotic spindle protein SPAG5/Astrin connects to the Usher protein network postmitotically. Cilia 2012, 1, 2. [CrossRef]

46. Liu, Y.; Wei, X.; Guan, L.; Xu, S.; Yuan, Y.; Lv, D.; He, X.; Zhan, J.; Kong, Y.; Guo, J.; et al. Unconventional myosin VIIA promotes melanoma progression. J. Cell Sci. 2018, 131. [CrossRef] [PubMed]

47. McKinnon, P.J. Ataxia-telangiectasia: An inherited disorder of ionizing-radiation sensitivity in man. Progress in the elucidation of the underlying biochemical defect. Hum. Genet. 1987, 75, 197-208. [CrossRef]

48. Foray, N.; Priestley, A.; Alsbeih, G.; Badie, C.; Capulas, E.P.; Arlett, C.F.; Malaise, E.P. Hypersensitivity of ataxia telangiectasia fibroblasts to ionizing radiation is associated with a repair deficiency of DNA double-strand breaks. Int. J. Radiat. Biol. 1997, 72, 271-283.

49. Le Guedard-Mereuze, S.; Vache, C.; Baux, D.; Faugere, V.; Larrieu, L.; Abadie, C.; Janecke, A.; Claustres, M.; Roux, A.F.; TufferyGiraud, S. Ex vivo splicing assays of mutations at noncanonical positions of splice sites in USHER genes. Hum. Mutat. 2010, 31, 347-355. [CrossRef]

50. Fertil, B.; Malaise, E.P. Inherent cellular radiosensitivity as a basic concept for human tumor radiotherapy. Int. J. Radiat. Oncol. Biol. Phys. 1981, 7, 621-629. [CrossRef]

51. Ristic, M.; Brockly, F.; Piechaczyk, M.; Bossis, G. Detection of Protein-Protein Interactions and Posttranslational Modifications Using the Proximity Ligation Assay: Application to the Study of the SUMO Pathway. Methods Mol. Biol. 2016, 1449, 279-290. [PubMed] 